NASA Contractor Report 198417

AIAA-96-0643

\title{
Screech Tones From Rectangular Jets With Spanwise Oblique Shock-Cell Structures
}

Ganesh Raman

NYMA, Inc.

Brook Park, Ohio

September 1996

Prepared for

Lewis Research Center

Under Contract NAS3-27186

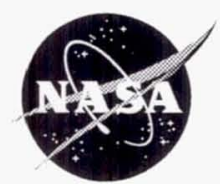

National Aeronautics and

Space Administration 


\title{
Screech tones from rectangular jets with spanwise oblique shock-cell structures
}

\author{
Ganesh Raman \\ NYMA Inc., Experimental Fluid Dynamics Section \\ NASA Lewis Research Center Group \\ Brook Park OH 44142
}

\begin{abstract}
Understanding screech is especially important for the design of advanced aircraft because screech can cause sonic fatigue failure of aircraft structures. Although the connection between shock-cell spacing and screech frequency is well understood, the relation between nonuniformities in the shock-cell structures and the resulting amplitude, mode, and steadiness of screech have remained unexplored. This paper addresses the above issues by intentionally producing spanwise (larger nozzle dimension) variations in the shock-cell structures and studying the resulting spanwise screech mode. The spanwise oblique shock-cell structures were produced using imperfectly expanded convergent-divergent rectangular nozzles (aspect ratio $=5$ ) with nonuniform exit geometries. Three geometries were studied: (a) a nozzle with a spanwise uniform edge, (b) a nozzle with a spanwise oblique (single bevelled) edge, and (c) a nozzle that had two spanwise oblique (double bevelled) cuts to form an arrowhead-shaped nozzle. For all nozzles considered, the screech mode was antisymmetric in the transverse (smaller nozzle dimension) direction allowing focus on changes in the spanwise direction. Three types of spanwise modes were observed:
\end{abstract}

symmetric (I), antisymmetric (II), and oblique (III). The following significant results emerged: (i) for all cases the screech mode corresponds with the spanwise shock-cell structure, (ii) when multiple screech modes are present, the technique presented here makes it possible to distinguish between coexisting and mutually exclusive modes, (iii) the strength of shocks 3 and 4 influences the screech source amplitude and determines whether screech is unsteady. The results presented here offer hope for a better understanding of screech and for tailoring shock-containing jets to minimize fatigue failure of aircraft components.

\section{Introduction}

\subsection{Motivation for the present work}

Rectangular supersonic jets with oblique or variable exits have applications in the propulsive systems of modern aircraft. The shock-cell structures and screech tone characteristics of jets from such unusual nozzles are unknown even though they significantly affect the design of nozzles and aircraft structures. Hay and Rose (1970) have documented that screech 
occurring in full-scale flight can damage the tailplane structure of an aircraft. They confirmed that the damage to a British Aircraft Corporation's VC 10 aircraft was indeed due to screech and not due to aerodynamic buffeting during reverse thrust. Of most concern was their finding that when the screech frequency matched a structural resonance frequency, the life-span of that structure was significantly reduced. Seiner, Manning, \& Ponton (1988) studied twin-jet screech resonance as it pertains to the high level dynamic loads in the inter nozzle region of aircraft such as the USAF's F-15 and B-1B. They also found that the dynamic loads associated with the screech resonance can reach levels capable of causing structural damage. Thus, to minimize potential structural damage, it is necessary that we understand the screech characteristics of rectangular jets from nonuniform geometries.

Interest in nonuniform jet exit geometries dates back to the early developmental stages of the Concorde (Westley \& Lilley (1952), Ffowcs Williams, Simson \& Virchis (1975), Smith (1989), Lilley (1991)). During noise reduction attempts with the Concorde, the Olympus engines were fitted with innovative variable geometry intake and exhaust nozzle assemblies. The variable exhaust nozzle could either close completely to reverse engine thrust or be only slightly closed to form a notch, thus squeezing the jet and altering the exit geometry. The exhaust flow from the nozzle became squeezed in the horizontal direction. The resultant flow asymmetry had little effect on the thrust but lowered the noise radiated to the side of the aircraft by $2-3 \mathrm{~dB}$. This led to considerable research work on notched nozzles (Hawkins \& Hoch (1971); Pannu and Johannesen (1976)). In recent years several researchers have tried to manipulate the internal contour of jet nozzles cleverly for thrust vectoring, enhanced mixing, and noise reduction. In the published literature such nozzles have been referred to as "asymmetric" (Wlezien \& Kibens (1988), Norum (1983)), "scarfed" (Lilley (1986)), and "bevelled" (Rice \& Raman (1993a,b), Rice (1995)). However, despite their benefits, such altered nozzles could screech differently, a concern that this paper addresses.

\subsection{Brief review of recent advances in understanding jet screech}

It is now well recognized that in imperfectly expanded jets, the screech tone is generated by coherent disturbances in the jets interacting with the shocks. The tone then propagates upstream (as feedback) to the jet exit and excites instabilities in the jet, thus closing the resonant loop. Pioneering work on screech was done by Powell (1953a,b), followed by investigations by Lassiter \& Hubbard (1954), and Davies \& Oldfield (1962a,b). Only a few of the many references on jet screech will be cited, but an extensive list of references is available in review articles by $\operatorname{Tam}(1991,1995)$. According to Professor Tam, screech is the least understood component of supersonic jet noise, and details of the screech generation process and the physics of mode changes (in circular jets) remain unknown (see Powell, Umeda \& Ishii (1992), and Panda (1995)). In addition, though models can predict the screech tone frequency (Tam (1988)), no model predicts amplitude or directivity of screech without recourse to empiricism. Screech, which is a special case of shock-associated noise (Harper-Bourne \& Fisher (1974), Howe \& Ffowcs Williams (1978), Tam, Seiner \& Yu (1986)), can also become intermittent and irregular. This was observed by Davies \& Oldfield (1962a,b), but the reason for the intermittency remains unknown. Considerable progress toward understanding these issues has been made in the recent detailed studies on rectangular jets by Umeda \& Yasuda (1990), Raman \& Rice (1994), Walker, Gordeyev \& Thomas (1995), Nishijima \& Kaji (1995), and Cain, Bower, Walker \& Lockwood (1995). However, despite this progress, many aspects of the above issues remain unresolved.

\subsection{Objectives of the present work}

Key to predicting screech is modeling the shock-cell structure of supersonic jets. Researchers

believe that changes in screech mode, amplitude, unsteadiness, and screech source structure are related to variations in shock-cell structures. In this connection considerable progress has been made in developing simple yet fairly accurate first-order estimates of the gross features of shock-cells and 
screech tone frequencies of supersonic jets (Tam, Jackson \& Seiner (1985), Tam (1988), Morris (1988), Morris, Bhat \& Chen (1989)). The present work provides some clues on the relationship between screech mode changes and the shock-cell structures by intentionally producing spanwise variations in the shock-cells and by studying changes in the spanwise screech mode. A rectangular geometry (aspect ratio $=5$ ) was chosen, where the screech modes are always antisymmetric in the smaller nozzle dimension, allowing us to focus on mode changes in the spanwise direction.

The present work, which studies screech tones from rectangular jets with spanwise nonuniform exits, considers three geometries: (a) a nozzle with a uniform straight edge, (b) a nozzle with a spanwise oblique (single bevelled) edge, and (c) a nozzle that has two equal and opposite spanwise oblique (double bevelled) edges that meet in the center to form an arrowhead-shaped nozzle. Throughout the text, the three nozzle types will be referred to by their respective letters. For all nozzles considered, the transverse dimension had straight sides. The nonuniform geometries produced spanwise oblique shock cells and spanwise instability modes. The modification of the shock-cells and instability modes altered the spanwise screech modes, the screech frequencies, and the screech amplitudes. The three types of spanwise modes observed-symmetric (I), antisymmetric (II), and oblique (III) - will be referred to by their respective Roman numerals. Although II was a special case of III, this distinction will be maintained throughout the paper. Under conditions where more than one screech mode was present, this study also addresses the issue of whether the modes coexisted or were mutually exclusive.

\subsection{Organization of the paper}

The paper begins with a description of rectangular supersonic jet nozzles with spanwise oblique geometries (section 2.1), followed by a description of the measurement and data analysis techniques (section 2.2). The general characteristics of rectangular jets with nonuniform exits are described in section 3.1, followed by a characterization of the spanwise varying screech modes (section 3.2 ). The relationship between spanwise screech modes and spanwise variations in the shock-cell structure is described in section 3.3. Screech unsteadiness and mode switching are discussed in section 3.4, followed by a discussion of the screech source structure, strength, and location in section 3.5. Finally the screech signature on a plane where damage is likely to occur from sonic fatigue is described in section 3.6.

\section{Experimental Apparatus and Procedure 2.1. Jet facility}

The experiments were carried out at the NASA Lewis Research Center Jet Facility. Since the facility was described earlier by Raman and Taghavi (1996), only a brief description is given here. The $76 \mathrm{~cm}$ diameter plenum tank was supplied with compressed air at pressures up to $875 \mathrm{kPa}$ (125 Psig) at $26.7^{\circ} \mathrm{C}\left(80^{\circ} \mathrm{F}\right)$. After passing through a filter that removed dirt or dust, air entered the plenum axially where it was laterally distributed by a perforated plate and a screen. Two circumferential splitter rings that contained acoustic treatment (kevlar) removed upstream valve noise. The flow was further conditioned by two 50 -mesh screens before exiting into the room through the nozzles. An automatic feedback control system maintained constant airsupply conditions. The control system could restrict pressure variations during each run to within $0.2 \%$. Such precise control was essential for this experiment since the screech tone was extremely sensitive to changes in operating conditions.

The three nozzle types (a-c) are depicted with dimensions (cm) in Fig. 1 (a-c). The nozzles were developed by Rice and used previously in the jet mixing and noise control studies of Rice \& Raman (1993a,b), and Rice (1995). Each nozzle included a circular-to-rectangular transition section and a converging-diverging nozzle contour, all integrated into one piece. The area ratio of the convergence, $A_{\text {circular }} / A^{*}$, was 2.38. The divergence area ratio, $\mathrm{A}_{\mathrm{e}} / \mathrm{A}^{*}$, was 1.128. Note that the subscript ' $\mathrm{e}$ ' and superscript ' $*$ ' refer to conditions at the nozzle exit and throat respectively. Also note that the convergence-divergence occurred only in one direction $(\mathrm{y})$ with straight side walls. As shown in 
Fig. $1(\mathrm{~b}, \mathrm{c})$ all bevel cuts were made at $30^{\circ}$ from the nozzle lip. The throat dimension for the three nozzles was $1.25,1.17$, and $1.17 \mathrm{~cm}$ for cases (a), (b), and (c) respectively. The nozzles, the probe traversing mechanism, and other reflective surfaces in the nearfield were covered with two layers of acoustically absorbent open-cell polyurethane foam (0.635 $\mathrm{cm}$ thick uncompressed). The idea was to minimize strong reflections from the nozzles and plenum. This material is known to be very effective in absorbing incident sound in the frequency range from $1000-25,000 \mathrm{~Hz}$ (with several layers, lower frequencies can also be absorbed).

\subsection{Measurement techniques}

A spark schlieren system was used for flow visualization. The system included a Palflash light source, a microscope objective, two spherical mirrors (15.24 cm dia., $91.44 \mathrm{~cm}$ focal length), and a vertical knife-edge. The light source consisted of an electricarc in an inert atmosphere of argon gas, and could produce a $1 \mu$ s pulse of high intensity light (4 Joules). Photographs were taken by allowing light from the knife-edge to fall directly on Polaroid film.

The acoustic measurements were made in the nearfield using $0.64 \mathrm{~cm}$ ( $1 / 4$ inch) dia. $B \& K$ microphones mounted under each nozzle and on a three-dimensional traversing mechanism for the nearfield noise surveys. The noise measurement planes are shown in Fig. 1 (d). The $B$ \& $K$ microphones were omnidirectional within $\pm 1 \mathrm{~dB}$ up to $10 \mathrm{kHz}$ and within $\pm 3 \mathrm{~dB}$ up to $20 \mathrm{kHz}$. The microphones were calibrated using a $B$ \& $K$ pistonphone calibrator, with corrections for day-today changes in atmospheric pressure. The sound pressure levels reported in this paper are in $\mathrm{dB}$ relative to $20 \mu \mathrm{Pa}$. The acoustic data were recorded using a $B \& K$ analyzer, and transient events were captured using a Spectral Dynamics instrument.

A short dual-cone static pressure probe designed by Pinckney (1975) at NASA Langley and used previously by Norum and Seiner (1982) was employed for the static pressure measurements in the jet. The static pressure measurement planes are shown in Fig. 1 (e). Because the static pressure rises sharply downstream of a shock, the static pressure probe could be used to map the spanwise variations in the shock-structure. The short static probe was less obtrusive than a longer version of this probe. However, when the short probe was calibrated against the more accurate longer version of this probe in a supersonic wind tunnel, the short probe was in error by as much as 7\% (Panda, private communication). Additional errors were caused by flow angularity downstream of the oblique shocks. Despite these errors, the static pressure maps do allow a qualitative comparison of the shock-cell structures for the cases under consideration.

\section{Discussion of Results}

\subsection{General characteristics of jets from rectangular nozzles with nonuniform exits}

Spark schlieren photographs of both the transverse and spanwise dimensions of the jet are shown for the three types of rectangular nozzles in Figs. 2-4. The photographs depict flows that are overexpanded $\left(M_{j}\right.$ $=1.2)$, perfectly expanded $\left(\mathrm{M}_{\mathrm{j}}=1.4\right)$, and underexpanded $\left(M_{j}=1.6\right)$, where $M_{j}$ represents the fully expanded jet Mach number. For the nozzle with a straight exit (Fig. 2), the shock strengths are minimized at the design point $\left(\mathrm{M}_{\mathrm{j}}=1.4\right)$ and weak Mach waves are visible. At $\mathrm{M}_{\mathrm{j}}=1.4$ the flow does not diverge significantly in the spanwise direction for the nonuniform nozzles (Figs. 3 and 4) because the spanwise pressure gradient cannot exert influence in a convergent-divergent nozzle operated at its design point. However, due to difficulties in designing complex C-D nozzles, the flow from the bevelled nozzles contained some shocks even at the design Mach number. The spanwise asymmetry in the shock-cell structures is clearly seen in Figs. 3 and 4.

The focus of this paper is the flow from imperfectly expanded convergent-divergent (C-D) nozzles. Two factors influenced the choice of C-D nozzles. First, C-D nozzles allow a study of overexpanded, design, and underexpanded conditions. Second, C-D nozzles operated slightly off-design have weak shocks that can be successfully modeled by linear shock-cell models (Howe \& Ffowcs Williams (1978), Tam et al. 
(1985), Tam (1988), Morris et al. (1989)).

\subsection{Characterization of spanwise varying screech modes}

The previous section described nozzle cases (a-c); screech characteristics for these nozzles are presented in Figs. 5-7. Information on the frequency, amplitude, and mode is presented in these figures. The Mach number axis is represented both as $\mathrm{M}_{\mathrm{j}}$ and as $\left|M_{d}{ }^{2}-M_{j}{ }^{2}\right|$, where $M_{d}$ and $M_{j}$ represent the design and fully expanded Mach numbers, respectively. The latter representation of the Mach number axis emphasizes the design point and allows comparisons between various degrees of over- and under- expansion. The data in Figs. 5-7 were obtained using three microphones (see sketch in Fig. 5 (c)) upstream of the nozzle exit. A pair of microphones measured the transverse phase difference $\left(\Delta \phi_{1}\right)$ and another the spanwise phase difference $\left(\Delta \phi_{2}\right)$. A common microphone was used as the reference microphone. All microphones were upstream $(x / h=-1.2)$ of the nozzle exit, and the spanwise and transverse microphone spacings were $\Delta \mathrm{z}=2.5 \mathrm{~h}$, and $\Delta \mathrm{y}=1.5 \mathrm{~h}$.

The key to understanding the frequency and amplitude information presented in Figs. 5-7 is the phase information in part (c) of each figure. The transverse phase difference $\left(\Delta \phi_{1}\right)$ was $+180^{\circ}$ (or $-180^{\circ}$ ) for all cases, indicating that the screech mode was antisymmetric in the transverse direction for all nozzles over the entire Mach number range. Therefore, the distinction between modes will be based only on their spanwise variations. For the spanwise phase difference $\left(\Delta \phi_{2}\right)$ there were three possibilities: $0^{\circ}$ that signified a spanwise symmetric mode (type I), $+180^{\circ}$ (or $-180^{\circ}$ ) that indicated the mode was spanwise antisymmetric (type II), non-zero and not $180^{\circ}$ that indicated the screech mode was spanwise oblique (type III).

For nozzle (a) (Fig. 5), the following comments are warranted. The symmetric mode (I) was present from $\mathrm{M}_{\mathrm{j}}=1.25$ to 1.82 . The corresponding Strouhal number range $\left(\mathrm{St}(\mathrm{h})=\mathrm{fh} / \mathrm{U}_{\mathrm{j}}\right.$, where $\mathrm{h}$ is the smaller nozzle dimension and $U_{j}$ is the fully expanded jet velocity) based on the frequencies in
Fig. 5 (a) was 0.28 to 0.06 . Over the $\mathrm{M}_{\mathrm{j}}$ range from 1.263 to $1.41(\mathrm{St}(\mathrm{h})=.28$ to 0.2$)$, the screech mode (I) weakened in amplitude (see Fig. 5 (b)) and a spanwise antisymmetric mode (II) appeared. The new result here is that even rectangular jets with straight exits can produce spanwise antisymmetric screech modes when the shock-cell structure is weakened near the nozzle design point. This observation has either gone unnoticed or has been ignored by previous researchers.

For the single bevelled nozzle, (b) (Fig. 6), there is a single spanwise oblique mode (IIIA) between $\mathrm{M}_{\mathrm{j}}$ $=1.27$ and $1.6(\mathrm{St}(\mathrm{h})=0.209-0.095)$. Another type IIIB mode appears at a different frequency between $\mathrm{M}_{\mathrm{j}}=1.38$ and $1.53(\mathrm{St}(\mathrm{h})=0.183$ to 0.135$)$. Note from Fig 6 (b) that IIIA is diminished when IIIB is at its maximum amplitude. Beyond $\mathrm{M}_{\mathrm{j}}=1.62$, both of the above modes disappear and a spanwise symmetric mode (I) appears. This type I mode is sustained from $\mathrm{M}_{\mathrm{j}}=1.62$ to $1.75(\mathrm{St}(\mathrm{h})=0.095$ to 0.07).

For the double bevelled nozzle, (c) (Fig. 7), below $\mathrm{M}_{\mathrm{j}}=1.42$ there is no screech. A spanwise antisymmetric mode (II) appears between $\mathrm{M}_{\mathrm{j}}=1.42$ and $1.66(\mathrm{St}(\mathrm{h})=0.228$ to 0.139$)$. For nozzle (c), it appears that the antisymmetric mode is formed by the superposition of two equal but opposite oblique waves produced by the oblique edges of the nozzle. Beyond $\mathrm{M}_{\mathrm{j}}=1.66$, a mode switch occurs, and the screech mode becomes spanwise symmetric (I). Note that there is a reduction in screech amplitude (Fig. 7 (b)) at the mode-switch point. The type I mode is sustained from $\mathrm{M}_{\mathrm{j}}=1.66$ to $1.87(\mathrm{St}(\mathrm{h})=$ 0.139 to 0.097 ). At high Mach numbers (approximately beyond $\mathrm{M}_{\mathrm{j}}=1.6$ ), the first shock turns into a normal shock (Mach disk). For all nozzles after the Mach disk forms, the screech mode becomes spanwise uniform.

For rectangular jets with uniform exits, the screech frequency ( $f$ ) can be predicted if the shock-cell spacing $(\lambda)$ is known (Tam (1988), Morris et al. (1989)). In such predictable cases the first four shock-cells are uniform and equally spaced. However, in the present case, due to spanwise variations and irregularities in the shock-cell structure, and the presence of multi-modes, the 
centerline average shock spacing is not a very meaningful indicator. A much more elaborate description (see shock patterns in Figs 2-4) is required to develop models that can predict the screech frequencies and modes that were measured in the present experiment.

The strengths of shocks 1-4 (measured on the jet's centerline) versus Mach number are given in Figure 8 (a-c) for the three cases under consideration. The shock strengths are given by $\gamma=\left(\mathrm{P}_{1}-\mathrm{P}_{0}\right) / \mathrm{P}_{0}$ where $\mathrm{P}_{1}$ and $\mathrm{P}_{\mathrm{o}}$ are the static pressures downstream and upstream of a shock. In the present argument the strengths of shocks 1-4 demonstrate the relationship between shock strength and screech tones. Although some researchers may believe that the connection between screech and shocks must be a complex phenomenon, the present data demonstrates clearly that a fairly simple but significant notion prevails: screech initiation and destabilization depends on shock strength.

First, from Fig. 8 (a-c) it is clear that the initiation of screech occurs only after a critical shock strength is reached. Second, when the shock structure is weakened (e.g., C-D nozzle operated at its design point), the main screech mode is destabilizied and an auxiliary screech mode appears. Finally, the formation of the Mach disk makes all screech modes spanwise uniform, regardless of nozzle geometry. The disappearance of screech at high $\mathrm{M}_{\mathrm{j}}$ (cessation) is not caused by decreasing shock strength. Screech cessation is attributed to diminished feedback and receptivity that occur at very high values of $\mathrm{M}_{\mathrm{j}}$ (see Raman (1996), and Cain \& Bower (1996)). An additional aspect revealed here is that, even within the $M_{j}$ range where strong screech occurs, a weakening of shocks 3 and 4 can destabilize screech.

Note also that the argument presented in the previous paragraph does not contradict Powell's (1953a,b) idea that the strongest screech tones are generated when the phases of pressures radiated from each shock-cell best reinforce each other at the nozzle exit. Although there are numerous sources, the effective source center depends only on one or two shock-cells (depending on $\mathrm{M}_{\mathrm{j}}$ ). Typically the $3 \mathrm{rd}$ or 4th shocks are the effective source centers, which is not difficult to comprehend because near the jet exit the shock strengths are very high, but the instabilities are still growing there. Far downstream the shock strengths diminish and the jet's coherent structure is also subject to dissipation. Consequently, the dominant acoustic center is at shock 3 or 4 (reported to be at shock 3 by Krothapalli et al. (1986)). When the source distribution displays a clear acoustic center, the problem is similar to that of an edgetone (Powell (1961); Karamcheti, Bauer, Shields, Stegen, \& Woolley (1969); Crighton (1992)). However, unlike the edgetone, the screech source location is a variable that depends on the jet's operating conditions and dimensions. The aforementioned trends are clearly borne out by the data. However, it is disappointing not to be able to make more definite quantitative predictions about screech using the shock strength values. The problem here is not the inadequacy of the experiment but our ignorance of the screech generation phenomenon. In a later section it will be shown that screech intermittency and peak source amplitude are dependent on the strengths of shocks 3 and 4 .

\subsection{Relationship between spanwise varying screech modes and spanwise oblique shocks}

A mode map summarizing previously described modes for nozzles (a-c) is given in Fig 9. We now direct attention to the connection between spanwise shock structure and screech modes. Static pressure maps depict the spanwise shock-cell structures for the three cases under consideration (see Figs. 10-12). Since the static pressure rises sharply downstream of a shock, details of the shock-cell structure are apparent from such maps. The measurement was made on an $\mathrm{xz}$ plane at $\mathrm{y} / \mathrm{h}=0$ (see Fig. 1 (e)). A typical measurement included 1071 data points (21 $x$ 51) with $\Delta x / h=0.15$, and $\Delta z / h=0.23$. Similar measurements made on the xy plane are not shown here. If we compare the mode map of Fig. 9 with the static pressure maps (Figs. 10-12), it is evident that for all three nozzles under consideration the screech modes corresponded with the spanwise shock-structure (i.e., spanwise uniform shocks produce spanwise uniform screech modes, and 
spanwise nonuniform shocks produce spanwise nonuniform screech modes). It also needs to be emphasized that the shock-cell structure, not the nozzle geometry, determined the spanwise screech mode. For example, the antisymmetric mode was produced by the double bevelled nozzle and by the nozzle with a straight-edged nozzle whose dominant screech mode had been destabilized. The spanwise oblique mode was produced by the nozzle with a spanwise oblique exit geometry until the Mach disk formed. The spanwise uniform mode was produced by the straight edged nozzle and by all nozzles after the Mach disk had formed, since the structure of downstream shocks was not influenced by nozzle geometry. As mentioned earlier, after the Mach disk formed, all modes were spanwise uniform regardless of nozzle geometry.

As regards the screech mode change, two types of mode switch are evident from the data of Figs. 6-8 (corresponding shock structure is depicted in Figs. 10-12). The first type occurs when the dominant screech mode is weakened (due to weakening of shocks) and an auxiliary screech mode appears. In section 3.4 it will be shown that the main and auxiliary screech modes can coexist or be mutually exclusive. The second type of mode switch occurs when one mode ceases to exist and another takes over. This type of switch occurs only when the formation of the Mach disk changes all spanwise nonuniform modes to spanwise uniform modes. The former type of mode switch is seen clearly for nozzles A (mode I to II), and B (mode IIIA to IIIB), and the latter type of mode switch is seen for nozzles B (mode III to I), and C (mode II to I). The above results suggest that a mode switch of the first type involves a switch in the effective screech source from one shock to another of a different structure, whereas a mode switch of the second type involves a change in the structure of the shock that plays the role of the effective source.

These results are significant for the general issue of screech mode change. For example, in a round jet, researchers are still puzzled about why and how mode staging occurs (Tam (1995); Powell et al. (1992)), although its occurrence has been documented by several investigators. It is not clear whether mode changes with increasing Mach number are due to changes in the evolution of coherent structures or due to changes in the shock-cell structure or whether one can even separate the two effects. In the present experiment the spanwise structure of the shock-cells was deliberately changed to study the resulting screech mode change. The spanwise variations in the shock-cells do change the screech modes accordingly. Although the round jet problem is not within the scope of the present work, the cases described here do provide some clues.

\subsection{Screech unsteadiness and mode switching}

The mode map (Fig. 9) illustrated that at certain operating conditions more than one screech mode can be present. The mode map was constructed using time-averaged data and therefore cannot reveal whether two modes are coexisting or switching in a mutually exclusive fashion. Walker et al. (1995) used the wavelet transform to address the timefrequency localization issue. In this paper the intermittency issue is addressed using 'instantaneous spectra'. The 'instantaneous spectra' were obtained by performing a Fast Fourier Transform (FFT) of smaller segments (with a $40 \%$ overlap) of a long time sequence ( 4.816 seconds). The FFT block size was 1024 and the sampling rate was $25.6 \mathrm{KHz}$, providing spectral data in a range from 0 to $10 \mathrm{KHz}$ with a frequency band width of $25 \mathrm{~Hz}$. The result is displayed as a 'waterfall' plot of 'instantaneous spectra'. Figures 13-15 show long time-averaged spectra (0 - $25.6 \mathrm{KHz}, 32 \mathrm{~Hz}$ band width) alongside 'instantaneous spectra' $(0-10 \mathrm{KHz}, 25 \mathrm{~Hz}$ band width) for all three nozzles over the Mach number range from 1.3-1.7. For the spanwise uniform nozzle both modes (types I and II) coexisted at $\mathrm{M}_{\mathrm{j}}=$ $1.3 \& 1.4$ (see Fig 13), beyond which only a steady single dominant mode was present. For the single bevelled nozzle, a weak screech mode (type IIIA) was present at $\mathrm{M}_{\mathrm{j}}=1.3$ (see Fig. 14). As this mode gained strength at $\mathrm{M}_{\mathrm{j}}=1.4$, another mode (type IIIB) appeared. At $\mathrm{M}_{\mathrm{j}}=1.5$ both oblique modes (IIIA,B) competed for dominance almost in a mutually exclusive manner. Beyond $\mathrm{M}_{\mathrm{j}}=1.6$ only a single mode (type I) was present, and that became irregular at $\mathrm{M}_{\mathrm{j}}=1.7$. 
Finally the double bevelled nozzle displayed very weak screech modes below $\mathrm{M}_{\mathrm{j}}=1.5$ (see Fig. 15). At $\mathrm{M}_{\mathrm{j}}=1.5$, the antisymmetric (II) screech mode was steady. The mode switch (from II to I) occurred around $\mathrm{M}_{\mathrm{j}}=1.6$, beyond which the spanwise uniform mode was very intermittent and irregular.

The reader is asked to refer back to Fig. 8 and observe that the amplitude and intermittency of screech are connected to the strengths of shocks 3 and 4. When the shock strength decreases, the screech amplitude diminishes. Evidence for the above trend can be found by comparing Fig. 8 (a) to Fig. 13. For the straight nozzle, at the design point $\left(M_{j}=1.4\right)$, the shock strength is minimized (Fig 8 (a)) resulting in a decrease in the screech amplitude (Fig. 13 (g)) and the appearance of mode II as discussed earlier. For the single bevelled nozzle the strengths of shocks 3 and 4 begin to diminish at $M_{j}$ $=1.5$ (Fig. 8 (b)), and this coincides with unstable competing modes in Fig. 14 (h). Finally for the double bevelled nozzle, the strength of the 4th shock is reduced beyond $\mathrm{M}_{\mathrm{j}}=1.6$, and the screech mode becomes irregular and intermittent (Fig. 15 (i,j)). The above examples demonstrate that the strengths of shocks 3 and 4 are indicative of the amplitude and steadiness of screech and should be considered as a factor in screech calculations.

\subsection{Screech source structure strength and location}

In sections $3.1-3.4$ screech mode results for nozzles $(a-c)$ over the entire range of Mach numbers were discussed; a single Mach number $\left(\mathrm{M}_{\mathrm{j}}=1.5\right)$ will now be described in detail. Contours for equal sound pressure levels at the screech frequency on the $\mathrm{xz}$ plane (see Fig. 1 (d)) are shown in Fig. 16. Similar measurements made on the xy plane are not shown here. Contours of low sound pressure levels are shown as dashed lines since our focus is on the effective sources that are given by the high amplitude islands. For the islands of contours under study, several observations can be made. For a nozzle with a straight exit (Fig. 16 (a)), these islands appear to be centered on the $\mathrm{z} / \mathrm{h}=0$ line, whereas for the single bevelled nozzle (Fig. 16 (b,c)) that produces oblique shocks, the high amplitude islands for both oblique modes (IIIA,B) are off-center and oblique in the spanwise direction. The most interesting case is that of the double bevelled nozzle (Fig. 16 (d)). Since this nozzle produces pairs of equal and opposite oblique shocks, two rows of high amplitude islands on either side of the spanwise centerline appear. The peak amplitude at the apparent screech source is highest for the nozzle with the straight edge (166.6 $\mathrm{dB})$. Corresponding peak levels for the single and double bevelled nozzles are $158.3 \mathrm{~dB}$ and $153.2 \mathrm{~dB}$. At $\mathrm{M}_{\mathrm{j}}=1.5$ the strengths $\left(\gamma=\left(\mathrm{P}_{1}-\mathrm{P}_{0}\right) / \mathrm{P}_{0}\right)$ of shocks 3 and 4 for the three nozzles were $1.213 \&$ $0.645,0.699 \& 0.174$, and $0.259 \& 0.133$ for nozzles 'a', 'b', and 'c', respectively. Finally, it must be pointed out that the correspondence between shock strength and screech source amplitude is clear only when other factors such as instability wave growth, feedback, and receptivity are not dominant factors in deciding the fate of screech.

Our source location results are not affected by the refraction of sound as it emerges from the jet (for a description of sound refraction by flow see Morris, Richarz \& Ribner (1973); Crighton (1975)). The refraction issue was further clarified by Professor Morris in a private communication, according to which: First, refraction by mean velocity takes some wavelengths to be seen. Second, there are no refraction effects due to mean velocity at $90^{\circ}$ to the flow direction. It follows that the source locations depicted in Fig. 16 are accurate.

The relative phase corresponding to the amplitude information of Fig. 16 is shown in Fig. 17. The phase data are shown only for $\mathrm{x} / \mathrm{h}=0$ to 4 . Although phase data was acquired for $\mathrm{x} / \mathrm{h}$ from 0 to 8 as in Fig. 16, credible phase data are available only for $\mathrm{x} / \mathrm{h}=0$ to 4 for the following reasons. The phase difference was obtained from a cross-spectrum (phase) between the moving microphone and a reference microphone upstream of the nozzle $(\mathrm{x} / \mathrm{h}=$ $-1.25, \mathrm{y} / \mathrm{h}=0.75, \mathrm{z} / \mathrm{h}=1.25$ ). The raw analysis provides data between $-180^{\circ}$ and $+180^{\circ}$. When one of these limits is exceeded there is an abrupt jump (readjustment) of the phase angle. In a simpler situation with continuous phase, it is easy to unwrap the phase and determine the proper quadrant for the phase data. In the present case there are actual 
jumps in phase near screech sources and across shocks. Thus in regions far downstream it is not always possible to distinguish a physical phase jump from one that is dependent on the instrument (see Rice and Taghavi (1992)). For this reason, data are shown only in regions where they are deemed credible. The isophase contours depict the spanwise screech mode (i.e., symmetric, oblique, \& antisymmetric). Note that the inclination of the phase lines in $17(b, c)$ is not the bevel angle of the nozzle but the spanwise angular orientation of the screech source in Fig. 16 (b,c). The shock strength variations in the spanwise direction corresponding to the amplitude and phase information of Figs. 16 and 17 are shown in Fig. 18. Part (a) of Figs 16-18 show that the source amplitude contours (Fig. 16 (a)), phase lines (Fig. 17 (a)) and shock-cells (Fig. 18 (a)) are all centered at and symmetric about $\mathrm{z} / \mathrm{h}=0$. Likewise, spanwise oblique sources (Fig. 16 (b,c)), and oblique phase lines (Fig. 17 (b,c)) correspond to oblique shock patterns (Fig. $18(\mathrm{~b}, \mathrm{c})$ ). Finally, the twin sources on either side of $\mathrm{z} / \mathrm{h}=0$ (Fig. 16 (d)) exhibit antisymmetric phase lines (Fig. 17 (d)) that correspond to the two equal and opposite shocks produced by the double bevelled nozzle (Fig. 18 (d)). The latter observation is justified by noting that two equal and opposite oblique modes at the same frequency combine to produce the antisymmetric mode. Thus, the screech mode is seen to correspond to the spanwise shock-cell structure. The importance of shock structure and strength was detailed earlier and will not be reiterated here.

\subsection{Screech signature on the "damage plane"}

After a discussion of screech source structure and strength to understand the phenomenon, it is now appropriate to consider damage factors. As stated in the introduction, one of the concerns is the propagation of screech upstream causing structural damage. The "damage plane" is where structural damage is likely to occur from sonic fatigue (see Fig 1 (d)) - the yz plane just behind the nozzle exit.

For the data shown in Fig. 19 the yz plane was located at $\mathrm{x} / \mathrm{h}=-1.2$. The sound pressure level and phase map on this plane for the three cases under consideration reveal several interesting features. For both the uniform and the single bevelled nozzles, the sound pressure level (SPL) peaks around $\mathrm{z} / \mathrm{h}=0$, whereas for the double bevelled nozzle the SPL exhibits a minima at $\mathrm{z} / \mathrm{h}=0$. For the latter nozzle the sound pressure level peaks are near the spanwise edges of the nozzle and are consistent with the source location shown in Fig. 16 (c). The phase data reveal a "null region" (where the phase does not change) for the nozzle with a straight edge. This "null region" was described in a previous paper (Raman and Taghavi (1996)) and is produced at high Mach numbers because as $\mathrm{M}_{\mathrm{j}}$ increases, the sources of screech move downstream, and therefore the wavefronts arriving at the nozzle exit plane would be flatter in the near nozzle region. Figure 19 (d-f) indicates the relative phase (with respect to a reference microphone) of a microphone that was moved in the yz plane. For the nozzle with a straight exit (Fig. 19 (d)) the phase variation in the $\mathrm{z} / \mathrm{h}$ direction (at $\mathrm{y} / \mathrm{h}=1$ ) is very small, because the screech mode is spanwise uniform. However, for the single bevelled nozzle (Fig. $19(\mathrm{e})$ ), at $\mathrm{y} / \mathrm{h}=1$, the phase variation in the $\mathrm{z} / \mathrm{h}$ direction is $90^{\circ}$ between $\mathrm{z} / \mathrm{h}=-4$ and +4 , and is indicative of a spanwise oblique mode. The spanwise phase difference is $180^{\circ}$ for the case of the double bevelled nozzle (19 (f)), indicating that the screech mode here is spanwise antisymmetric. Thus, the phase for the single and double bevelled nozzles exhibits a spanwise oblique and spanwise antisymmetric variation, respectively. The amplitude and phase information provided in this figure will be useful for assessing the potential damage from these nozzles as well as designing strategies including active control to minimize screech damage.

\section{Concluding remarks}

A detailed investigation was conducted on the screech tones from rectangular jets with spanwise nonuniform exits. The primary motivation was the unexplored connection between shock-cell structure and screech modes. The secondary motivation was the lack of data on the screech characteristics of rectangular jets with spanwise oblique shock-cell structures. 
Three types of spanwise modes were observed: symmetric, antisymmetric, and

oblique. The mode observed corresponded with the spanwise shock-cell structure. In cases where more than one mode was present, the technique presented here makes it possible to distinguish coexisting and mutually exclusive modes. The strengths of shocks 3 and 4 determined the screech source amplitude, and the unsteadiness of screech. Jets with spanwise oblique shock-cell structures produced screech that was generally weaker and more unsteady than jets with spanwise uniform shock-cells. In addition, jets from nonuniform nozzles screeched only over a limited Mach number range. The results presented provide answers to some of the issues relating to screech, and offer hope for a better understanding of screech and for tailoring shock containing jets that minimize fatigue failure of aircraft components.

\section{Acknowledgements}

The work reported in this paper was an outgrowth of shear flow control efforts initiated by Dr. E.J. Rice at the NASA Lewis Research Center. I would like to thank Prof. C.K.W. Tam for many insightful discussions, and for his encouragement. Prof. P.J. Morris clarified the refraction issue. Dr. J. Panda's help with the schlieren photography is gratefully acknowledged.

\section{References}

Cain, A.B., Bower, W.W., Walker, S.H. \& Lockwood, M.K. 1995 Modeling supersonic jet screech. part 1: vortical instability wave modeling. AIAA Paper 95-0506.

Cain, A.B. \& Bower, W.W. 1996 Modeling supersonic jet screech: differential entrainment and amplitude effects. AIAA Paper 96-0916.

Crighton, D.G. 1975 Basic principles of aerodynamic noise generation. Prog. Aerospace Sci. $16,31-96$.

Crighton, D.G. 1992 The edge-tone feedback cycle; linear theory for the operating stages. J. Fluid Mech. 234, 361-391.
Davies, M.G. \& Oldfield, D.E.S. 1962a Tones from a choked axisymmetric jet. I. cell

structure, eddy velocity and source locations. Acustica 12, 257-266.

Davies, M.G. \& Oldfield, D.E.S. $1962 b$ Tones from a choked axisymmetric jet. II. the self excited loop and mode of oscillation. Acustica 12, 267-277.

Ffowcs Williams, J.E., Simson, J. \& Virchis, V.J. 1975 'Crackle' : an annoying component of jet noise. J. Fluid Mech. 71, 251-271.

Harper-Bourne, M. \& Fisher, M.J. 1974 The noise from shock waves in supersonic jets. Noise mechanisms, AGARD CP 131, 11-1 to 11-13.

Hawkins, R. \& Hoch, R. 1971 Studies into Concorde's engine noise emission and reduction. 10th Int. Aero. Cong., Paris.

Howe, M.S. \& Ffowcs Williams, J.E. 1978 On the noise generated by an imperfectly expanded supersonic jet. Phil. Trans. Royal Soc. Lond. 289, Ser A, 1358, 271-314.

Hay, J.A. \& Rose, E.G. 1970 In-flight shock cell noise. J. Sound Vib. 11, 411-420.

Karamcheti, K., Bauer, A., Shields, W.L., Stegen, G. \& Woolley, P.J. 1969 Some features of an edge tone flowfield. NASA SP 207.

Krothapalli, A., Hsia, Y., Baganoff, D. \& Karamcheti, K. 1986 The role of screech tones in the mixing of an underexpanded rectangular jet. J. Sound Vib. 106, 119-143.

Lassiter, L.W. \& Hubbard, H.H. 1954 The near noise field of static jets and some model studies of devices for noise reduction. NACA TN 3187.

Lilley, J.S. 1986 The design and optimization of propulsion systems employing scarfed nozzles. J. Spacecraft and Rockets 23, 597-604.

Lilley, G.M. 1991 Jet noise classical theory and experiments. aeroacoustics of flight vehicles: theory 
and practice, Vol. 1: noise sources, NASA RP 1258, WRDC TR 90-3052, H.H. Hubbard, Ed., 211-289.

Morris, P.J., Richarz, W. \& Ribner, H.S. 1973 Reduction of peak jet noise using jet refraction. J. Sound Vib. 29, 443-455.

Morris, P.J., 1988 A note on the effect of forward flight on shock-spacing in circular jets. J. Sound Vib. 122, 175-178.

Morris, P.J., Bhat, T.R.S., \& Chen, G. 1989 A linear shock cell model for jets of arbitrary exit geometry. J. Sound Vib. 132, 199-211.

Nishijima, N. \& Kaji, S. 1995 Flow and acoustic fields of rectangular supersonic jet in screech. high speed jet flows (eds. Raman et al.) ASME FED 214, 109-114.

Norum, T.D. \& Seiner, J.M. 1982 Measurements of mean static pressure and far field acoustics of shock containing supersonic jets. NASA TM 84521 .

Norum, T.D. 1983 Screech suppression in supersonic jets. AIAA J. 21, 235-240.

Panda, J. 1995 Measurement of shock oscillation in underexpanded supersonic jets. AIAA Paper 95-2145.

Pannu, S.S. \& Johannesen, N.H. 1976 The structure of jets from notched nozzles. J. Fluid Mech. 74, 515528.

Pinckney, S.Z. 1975 A short static-pressure probe design for supersonic flow. NASA TN-D 7978.

Powell, A. 1953a On the noise emanating from a two-dimensional jet above the critical pressure. Aeronaut. Q. 4, 103-122.

Powell, A. 1953b On the mechanism of choked jet noise. Proc. Phys. Soc. London 66, 1039-1056.

Powell, A. 1961 On the edgetone. J. Acoust. Soc. Amer. 33, 395-409.

Powell, A., Umeda, Y. \& Ishii, R. 1992
Observations of the oscillation modes of choked circular jets. J. Acoust. Soc. Amer. 92, 2823-2836.

Raman, G. \& Rice, E.J. 1994 Instability modes excited by natural screech tones in a supersonic rectangular jet. Phys. Fluids 6, 3999-4008.

Raman, G. \& Taghavi, R. 1996 Resonant interaction of a linear array of supersonic rectangular jets: an experimental study. J. Fluid Mech. 309, 93-111.

Raman, G. 1996 Cessation of screech in underexpanded jets. AIAA Paper 96-1719 (also NASA CR 198475).

Rice, E.J. \& Taghavi, R. 1992 Screech noise source structure of a supersonic rectangular jet. AIAA Paper 92-0503.

Rice, E.J. \& Raman, G. 1993a Mixing noise reduction for rectangular supersonic jets by nozzle shaping and induced screech mixing. AIAA Paper 93-4322 (also NASA TM 106364).

Rice, E.J. \& Raman, G. 1993b Supersonic jets from bevelled rectangular nozzles. ASME Paper 93WA/NCA-26 (also NASA TM 106403).

Rice, E.J. 1995 Jet mixer noise suppressor using acoustic feedback. US patents 5,325,661 and $5,392,597$.

Seiner, J.M., Manning, J.C. \& Ponton, M.K. 1988 Dynamic pressure loads associated with twin supersonic plume resonance. AIAA J. 26, 954-960.

Smith, M.J.T. 1989 Aircraft noise. Cambridge University Press.

Tam, C.K.W., Jackson, J.A. \& Seiner, J.M. 1985 A multiple-scales model of shock-cell structure of imperfectly expanded supersonic jets. J. Fluid Mech. 153, 123-149.

Tam, C.K.W., Seiner, J.M. \& Yu, J.C. 1986 Proposed relationship between broadband shock associated noise and screech tones. J. Sound Vib. 110, 309-321. 
Tam, C.K.W. 1988 The shock-cell structures and screech tone frequencies of rectangular and nonaxisymmetric supersonic jets. J. Sound Vib. 121, 135-147.

Tam, C.K.W. 1991 Jet noise generated by largescale coherent motion. aeroacoustics of flight vehicles: theory and practice, Vol. 1: noise sources, NASA RP 1258, WRDC TR 90-3052, H.H. Hubbard, Ed., 311-390.

Tam, C.K.W. 1995 Supersonic jet noise. Ann. Rev. Fluid Mech. 27, 17-43.

Umeda, Y. \& Yasuda, A. 1990 Instability of astrophysical jets. II numerical simulation of twodimensional underexpanded slab jets. Progress of Theoretical Physics, 84, 5, 856-866.

Walker, S.H., Gordeyev, S.V. \& Thomas, F.O. 1995 A wavelet transform analysis applied to unsteady jet screech resonance. high speed jet flows (eds. Raman et al.) ASME FED 214, 103-108.

Westley, R. \& Lilley, G.M. 1952 An investigation of the noise field from a small jet and methods for its reduction. Rep. No. 53, College of Aeronautics, Cranfield (England).

Wlezien, R.W. \& Kibens, V. 1988 Influence of nozzle asymmetry on supersonic jets. AIAA J. 26, 27-33. 
-5.08 diam (typical)
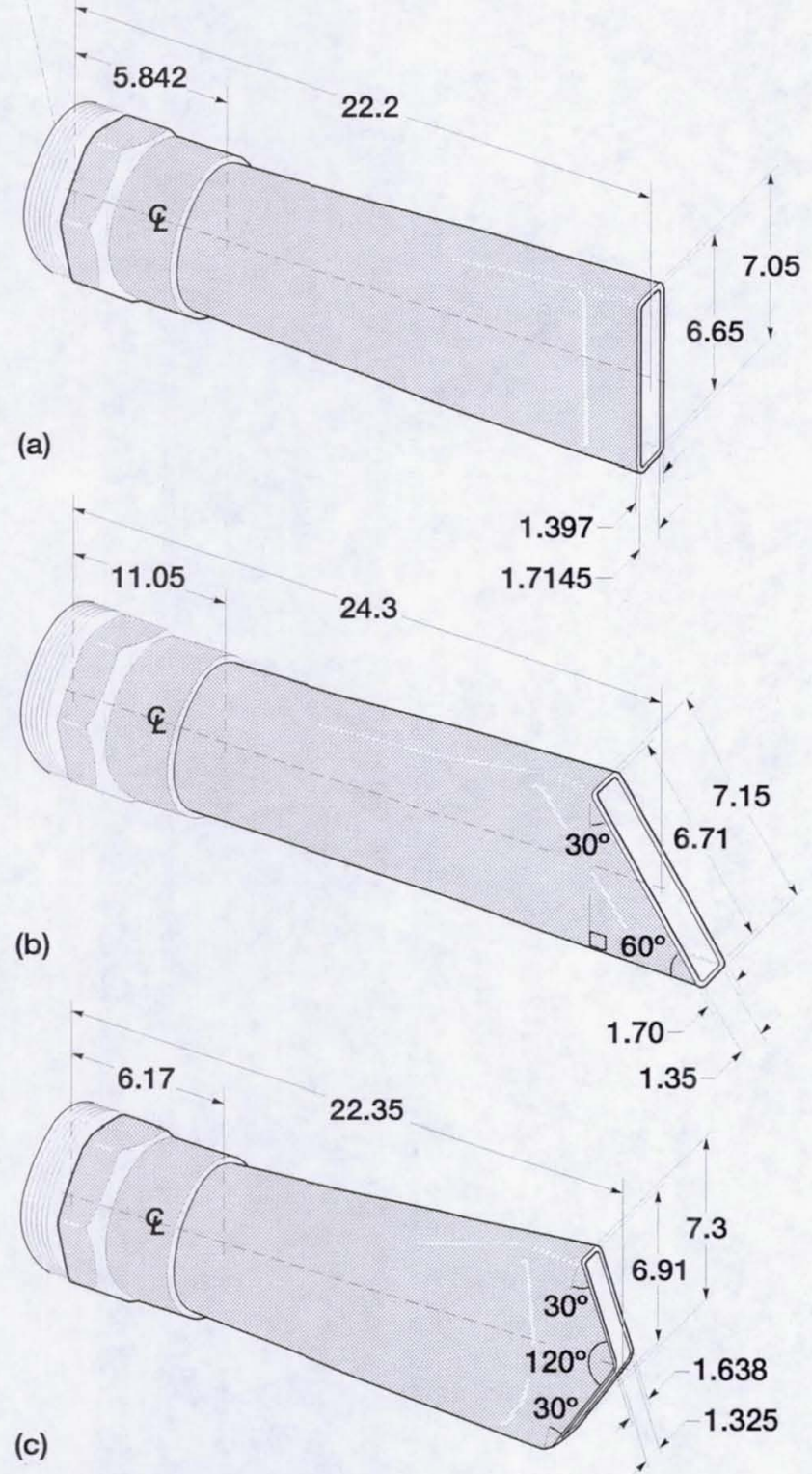

(d)

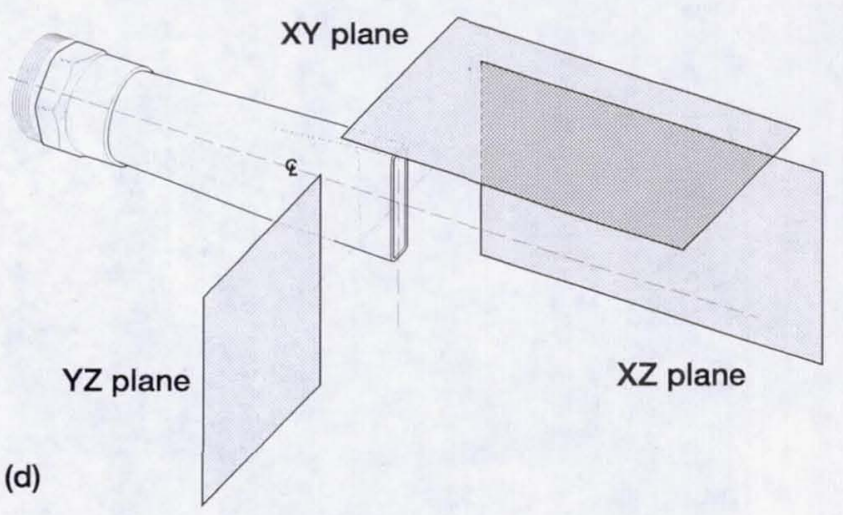

(e)
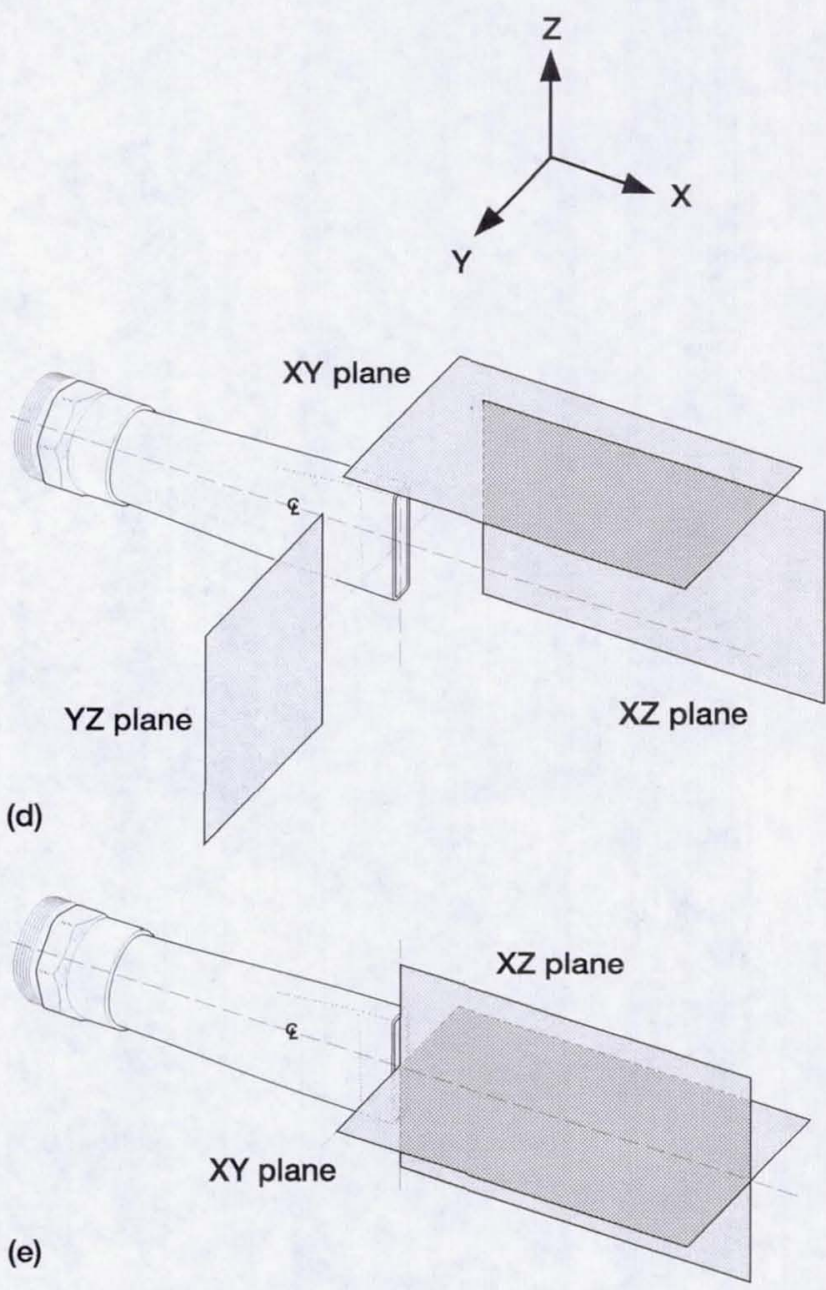

Figure 1.-Nozzles and measurement planes (dimensions are in centimeters). (a) Spanwise uniform nozzle, (b) Single bevelled nozzle, (c) Double bevelled nozzle, (d) Noise measurement planes, (e) Static pressure measurement planes. 


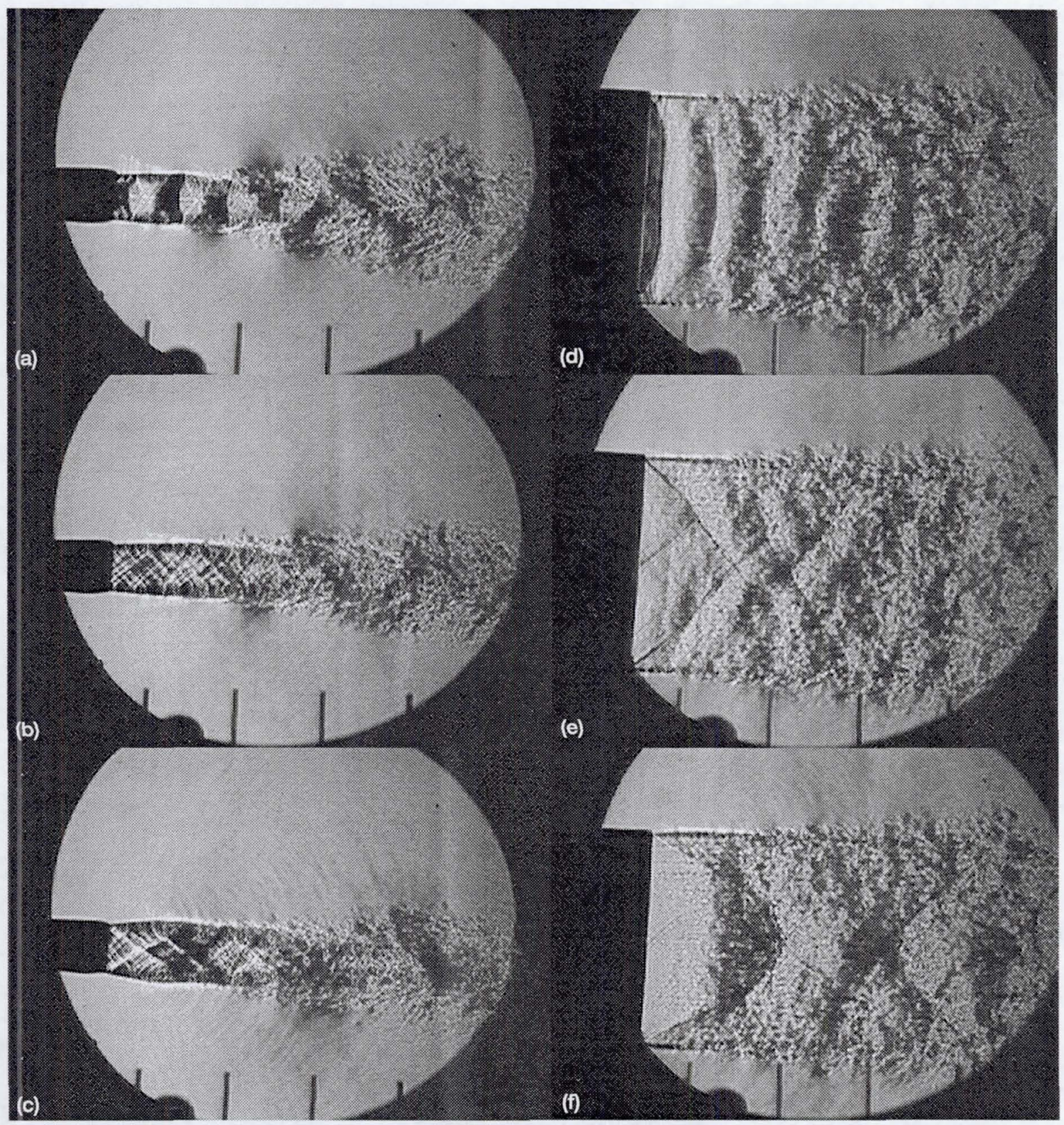

Figure 2.-Spark schlieren images of over-, ideally-, and under-expanded jets from a rectangular convergentdivergent nozzle with a straight exit (both narrow and wide dimensions of the nozzle are shown). $M_{j}(a, d) 1.2$, (b,e) 1.4, (c,f) 1.6 . 


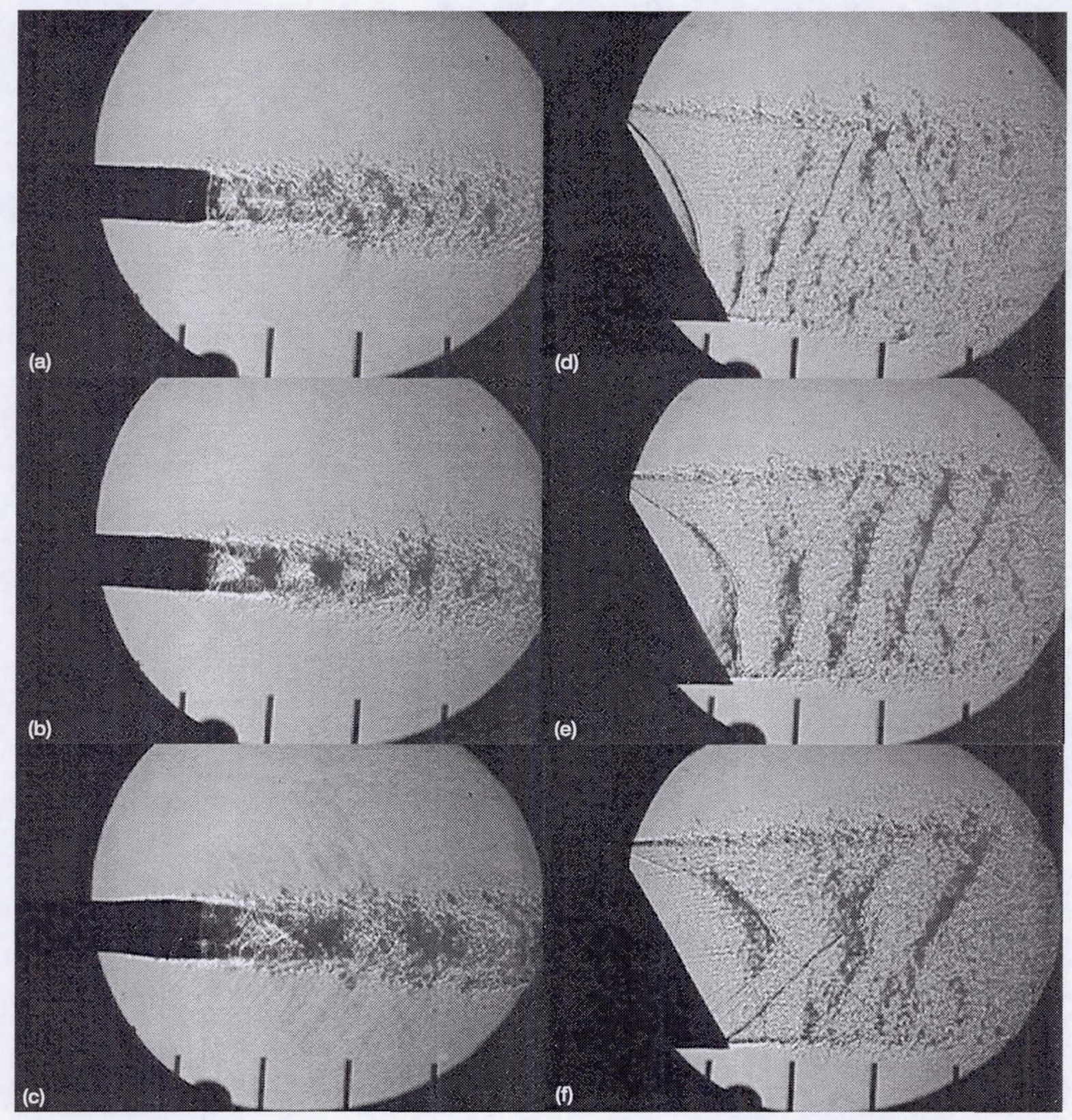

Figure 3.-Spark schlieren images of over-, ideally-, and under-expanded jets from a rectangular convergentdivergent nozzle with a single bevelled exit (both narrow and wide dimensions of the nozzle are shown). $\mathrm{M}_{\mathrm{j}}$ (a,d) 1.2, (b,e) 1.4, (c,f) 1.6. 


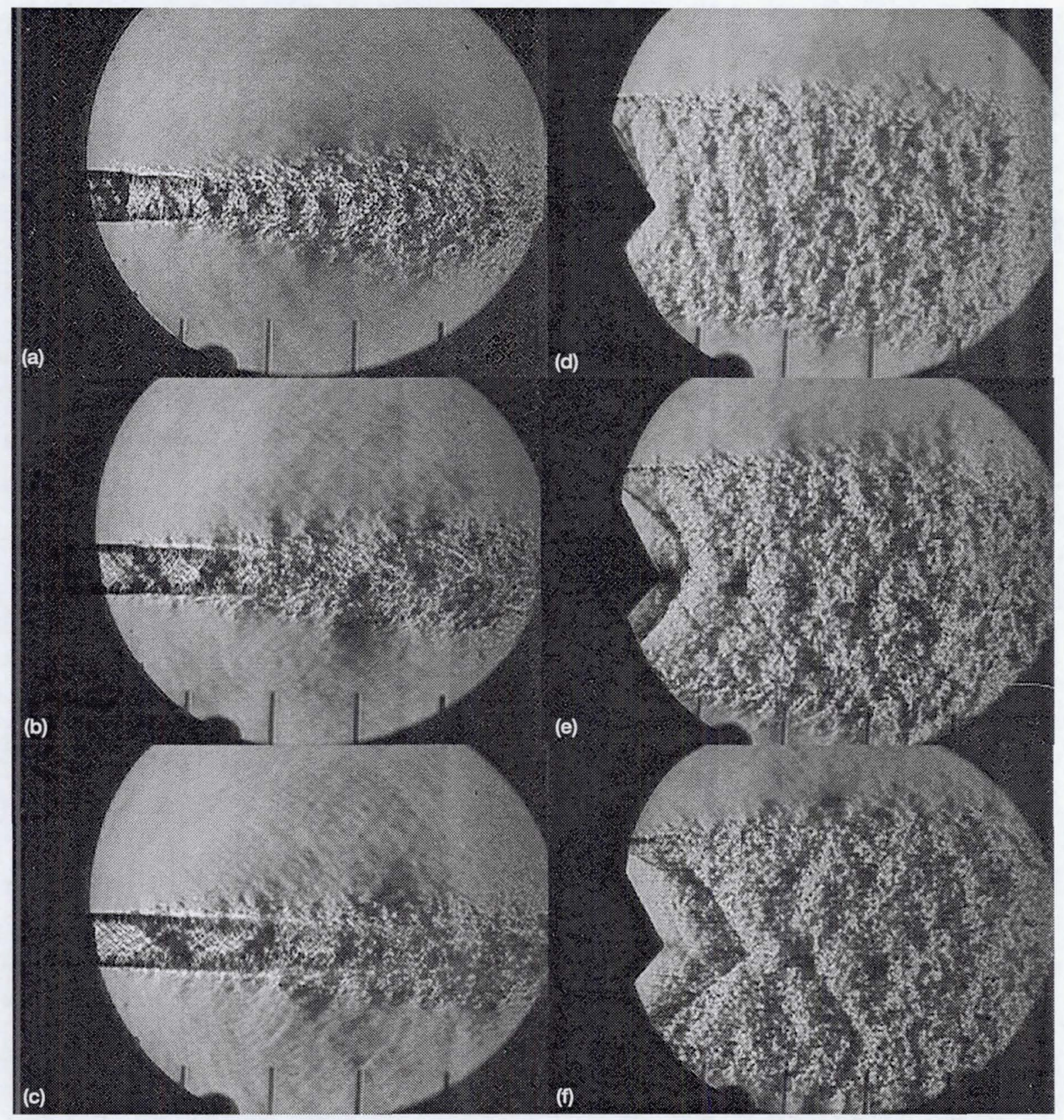

Figure 4.-Spark schlieren images of over-, ideally-, and under-expanded jets from a rectangular convergentdivergent nozzle with a double bevelled exit (both narrow and wide dimensions of the nozzle are shown). $M_{j}$ (a,d) 1.2, (b,e) 1.4, (c,f) 1.6 . 

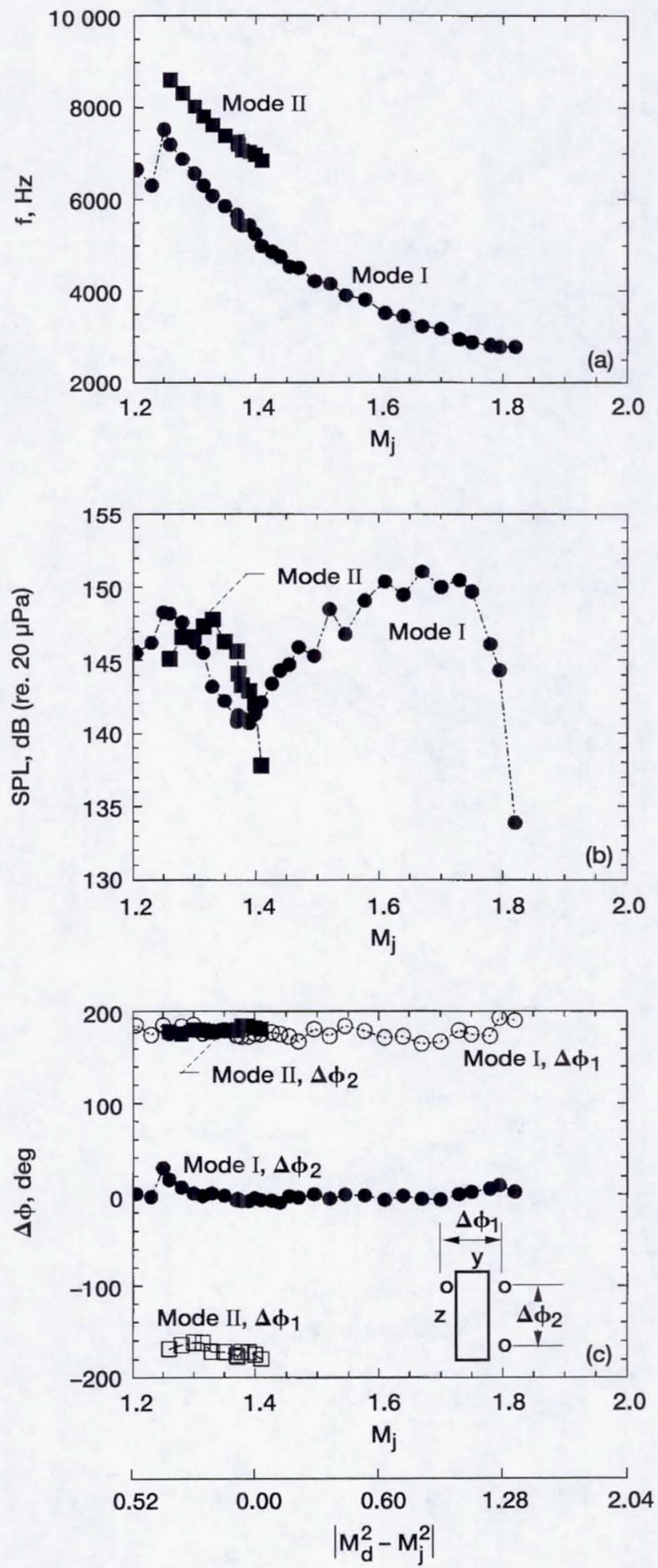

Figure 5.-Screech tone characteristics of a rectangular convergent-divergent nozzle with a straight exit. (a) Screech frequency, (b) Screech sound pressure level measured at the jet lip, (c) Phase difference in the transverse and spanwise directions, versus the fully expanded jet Mach number. 

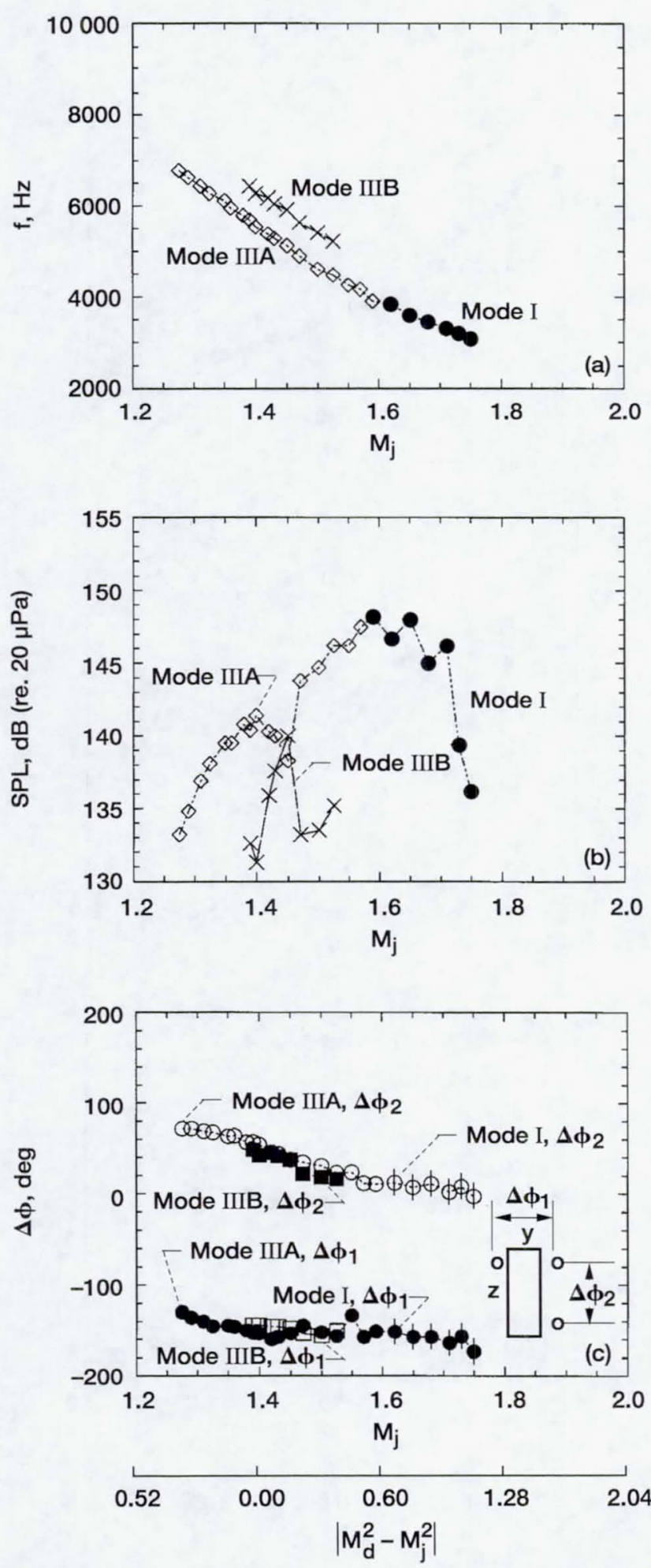

Figure 6.-Screech tone characteristics of a rectangular convergent-divergent nozzle with a single bevelled exit. (a) Screech frequency, (b) Screech sound pressure level measured at the jet lip, (c) Phase difference in the transverse and spanwise directions, versus the fully expanded jet Mach number. 

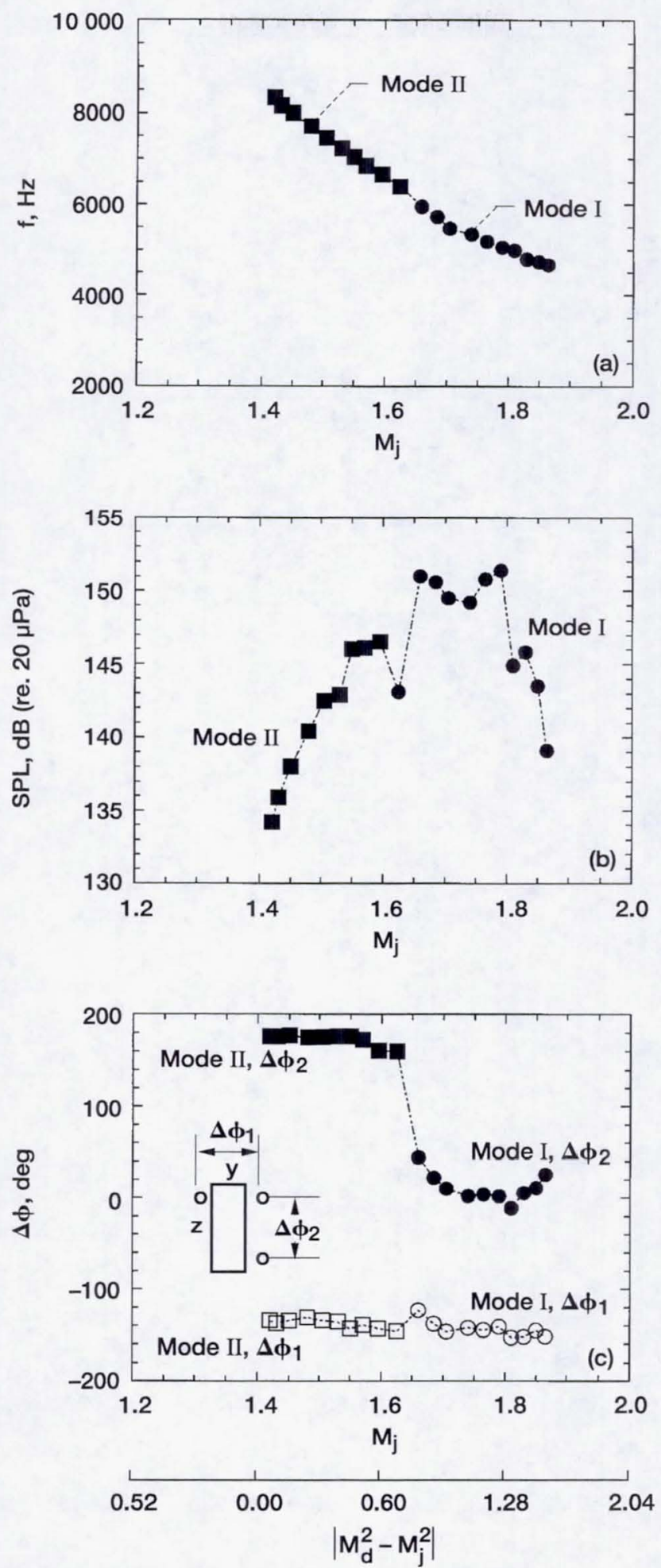

Figure 7.-Screech tone characteristics of a rectangular convergent-divergent nozzle with a double bevelled exit. (a) Screech frequency, (b) Screech sound pressure level measured at the jet lip, (c) Phase difference in the transverse and spanwise directions, versus the fully expanded jet Mach number. 

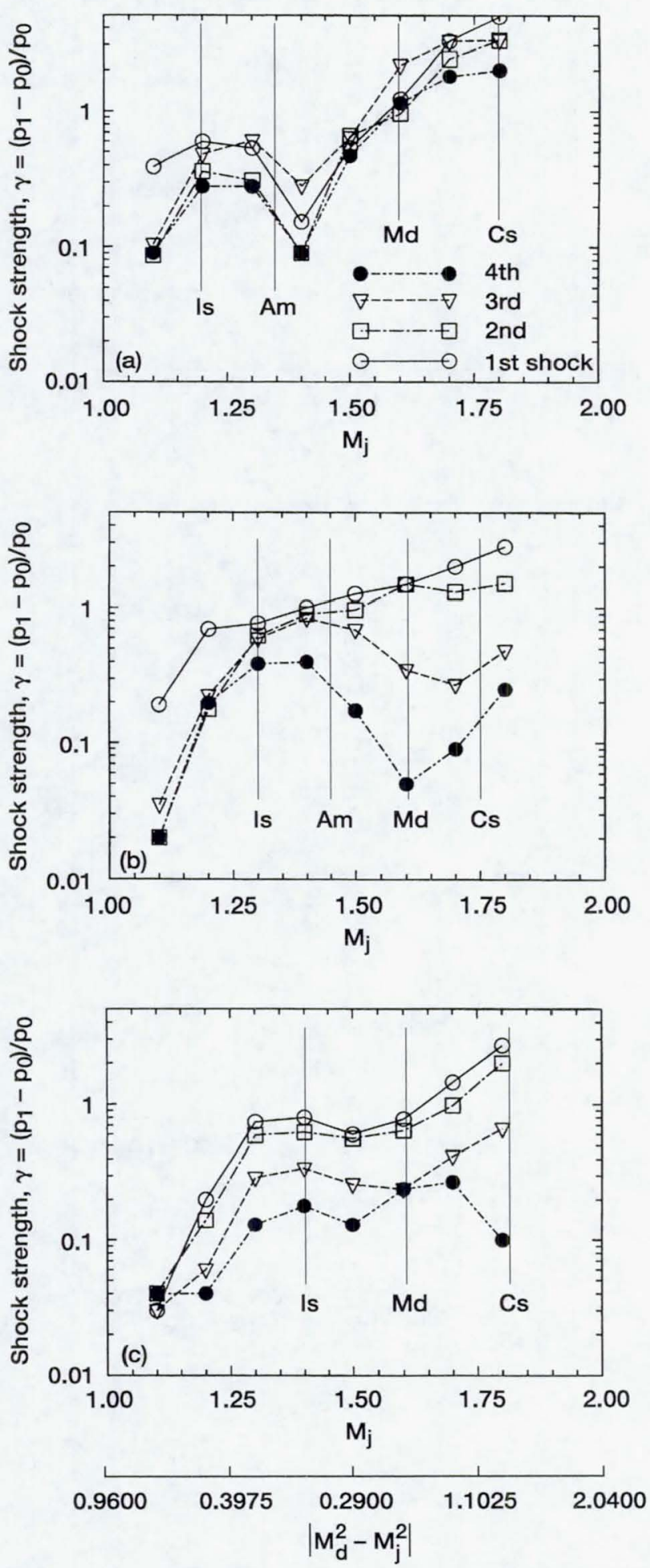

Figure 8.-Shock strength versus fully expanded jet Mach number. (a) Rectangular nozzle with a straight exit, (b) Single bevelled nozzle, (c) Double bevelled nozzle. (Is-initiation of screech, Am-auxiliary screech mode appears, Md-Mach disk forms, Cs-cessation of screech). 
Mode I: Spanwise symmetric

- Mode II: Spanwise antisymmetric

Mode III (A \& B): Spanwise oblique

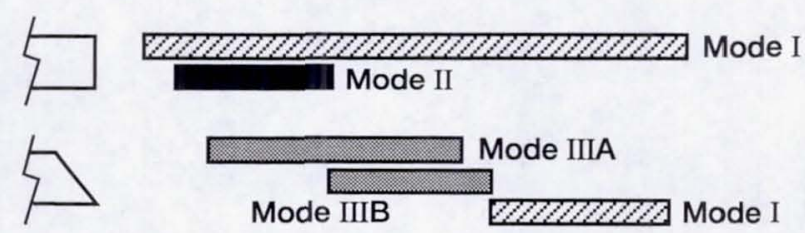

5

Mode II

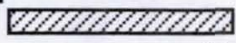

Mode I
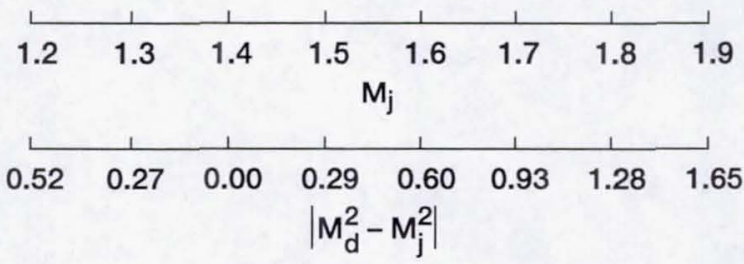

Figure 9.-Mode diagram for rectangular jets with spanwise oblique nozzle exit geometries. 

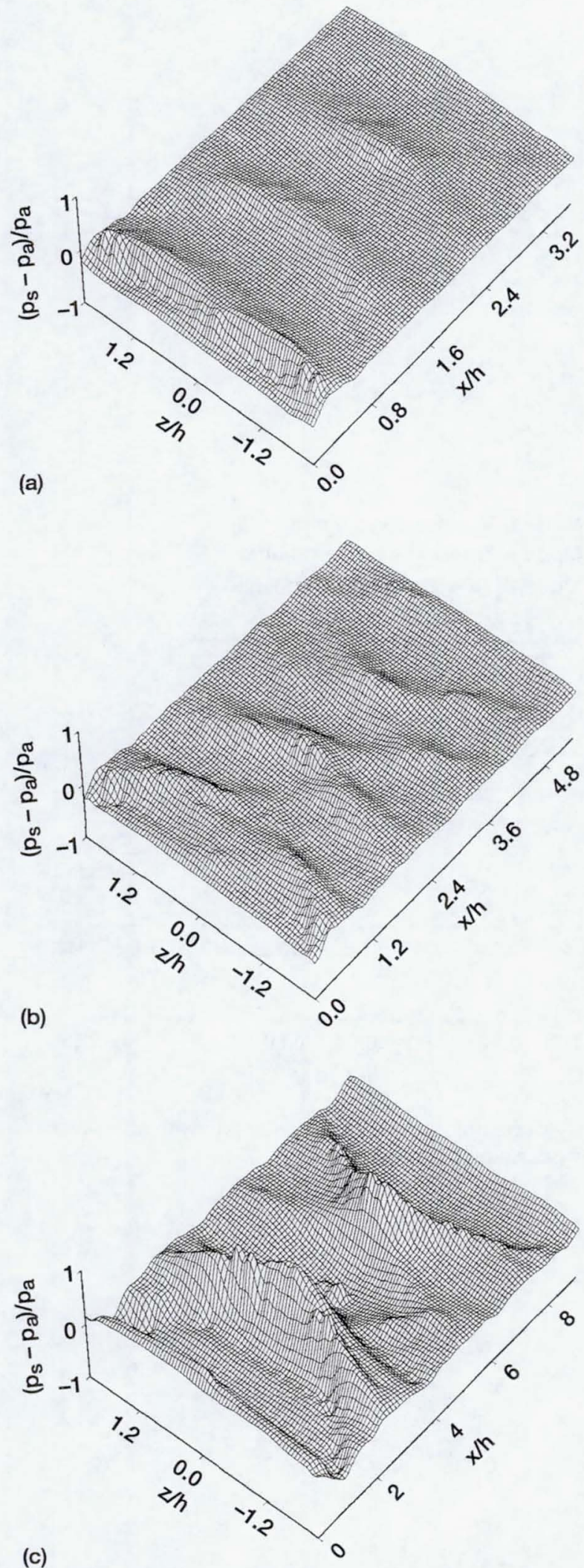

Figure 10.-Spanwise variations in the shock-cell structure for a jet from a rectangular nozzle with a straight exit.

$x z$ plane was located at $y / h=0 . M_{j}$ (a) 1.2, (b) 1.3, (c) 1.7. 

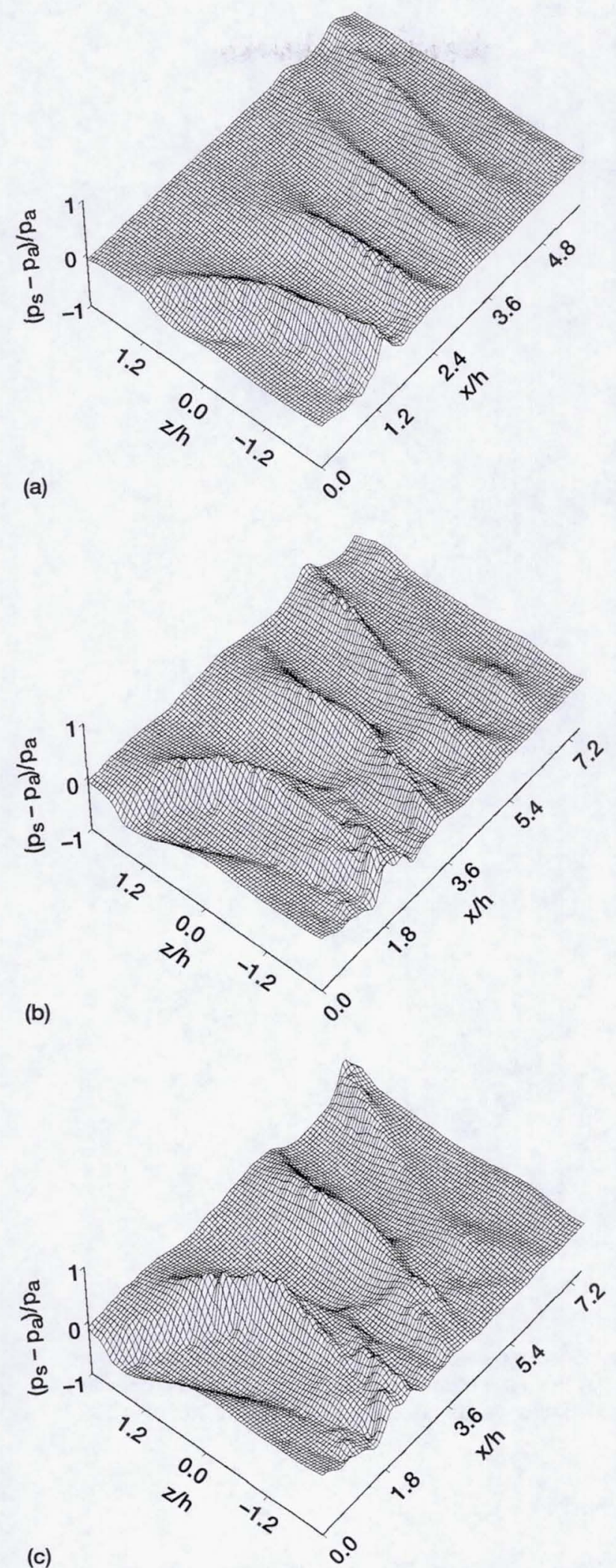

Figure 11.-Spanwise variations in the shock-cell structure for a jet from a rectangular nozzle with a single bevelled exit. $x z$ plane was located at $y / h=0 . M_{j}$ (a) 1.3, (b) 1.5,

(c) 1.6. 

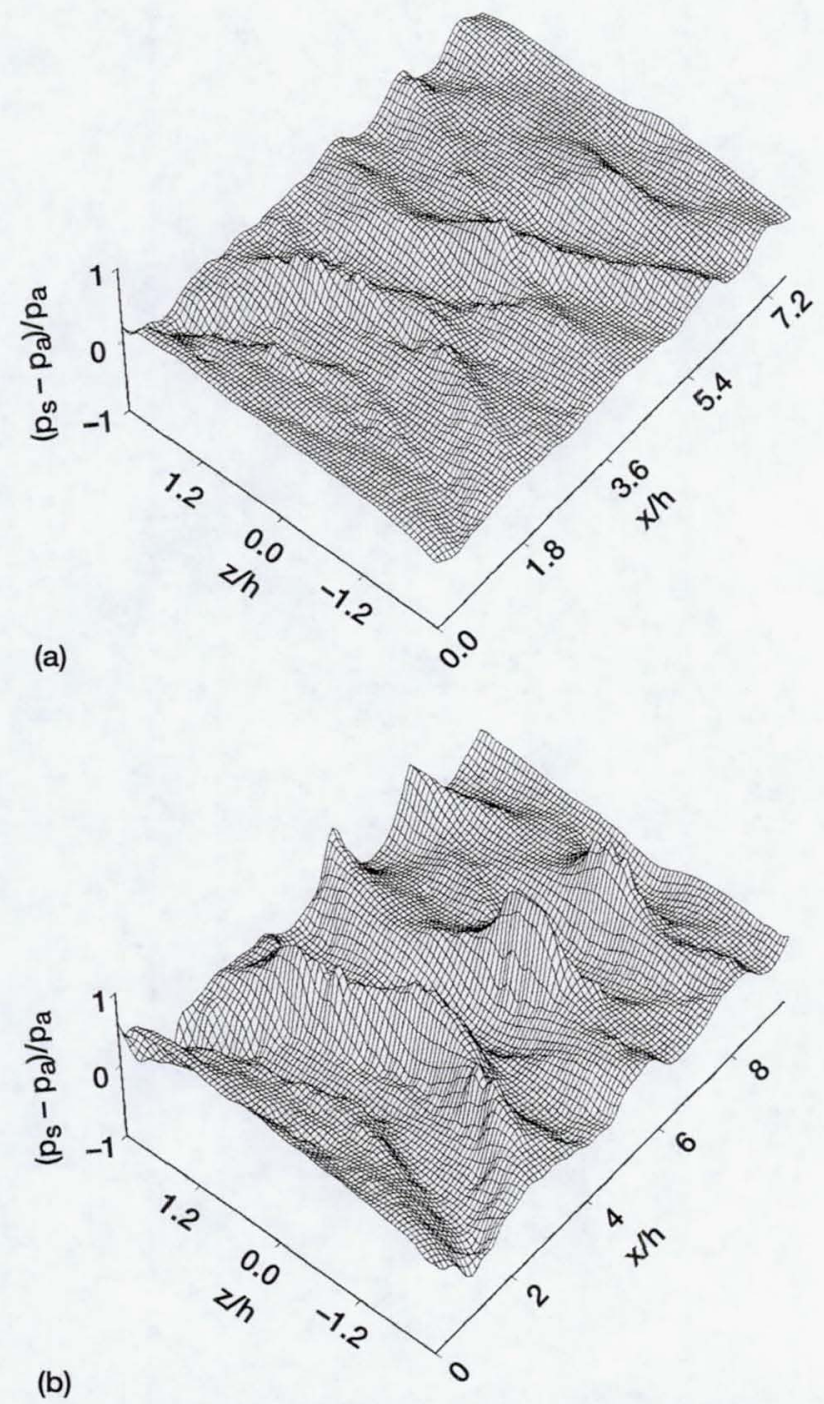

Figure 12.-Spanwise variations in the shock-cell structure for a jet from a rectangular nozzle with a double bevelled exit. $x z$ plane was located at $y / h=0 . M_{j}$ (a) 1.5, (b) 1.7. 

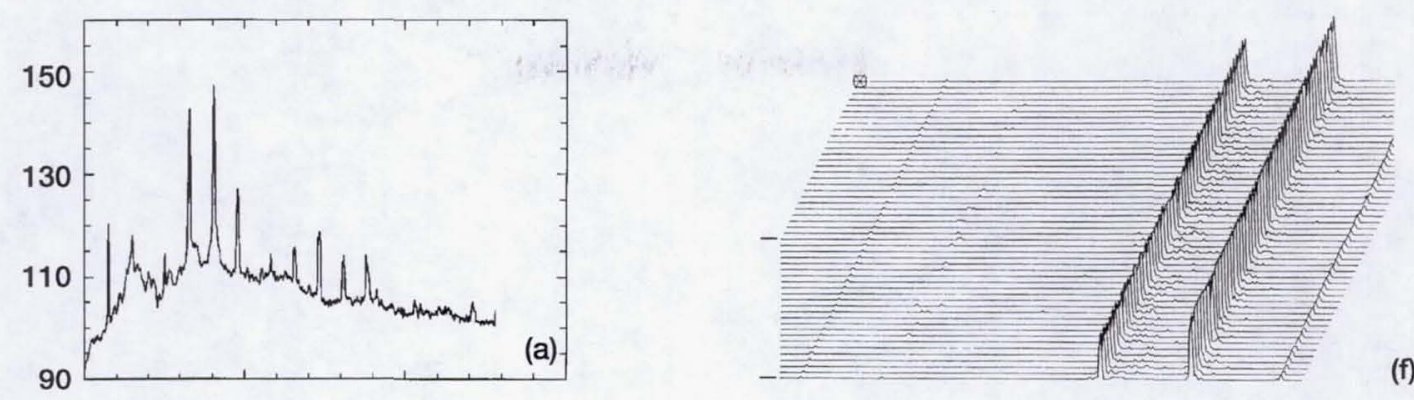

(f)
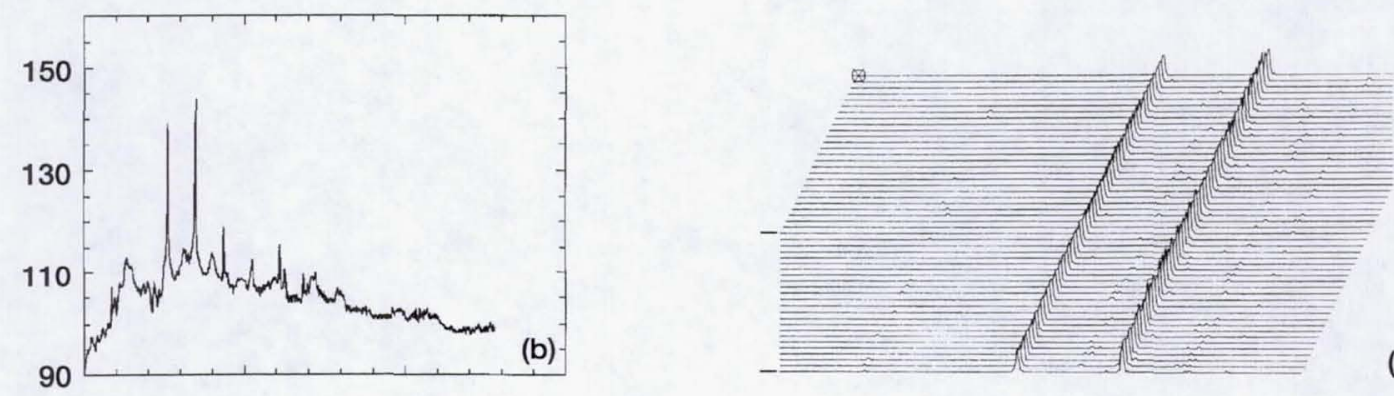

(g)
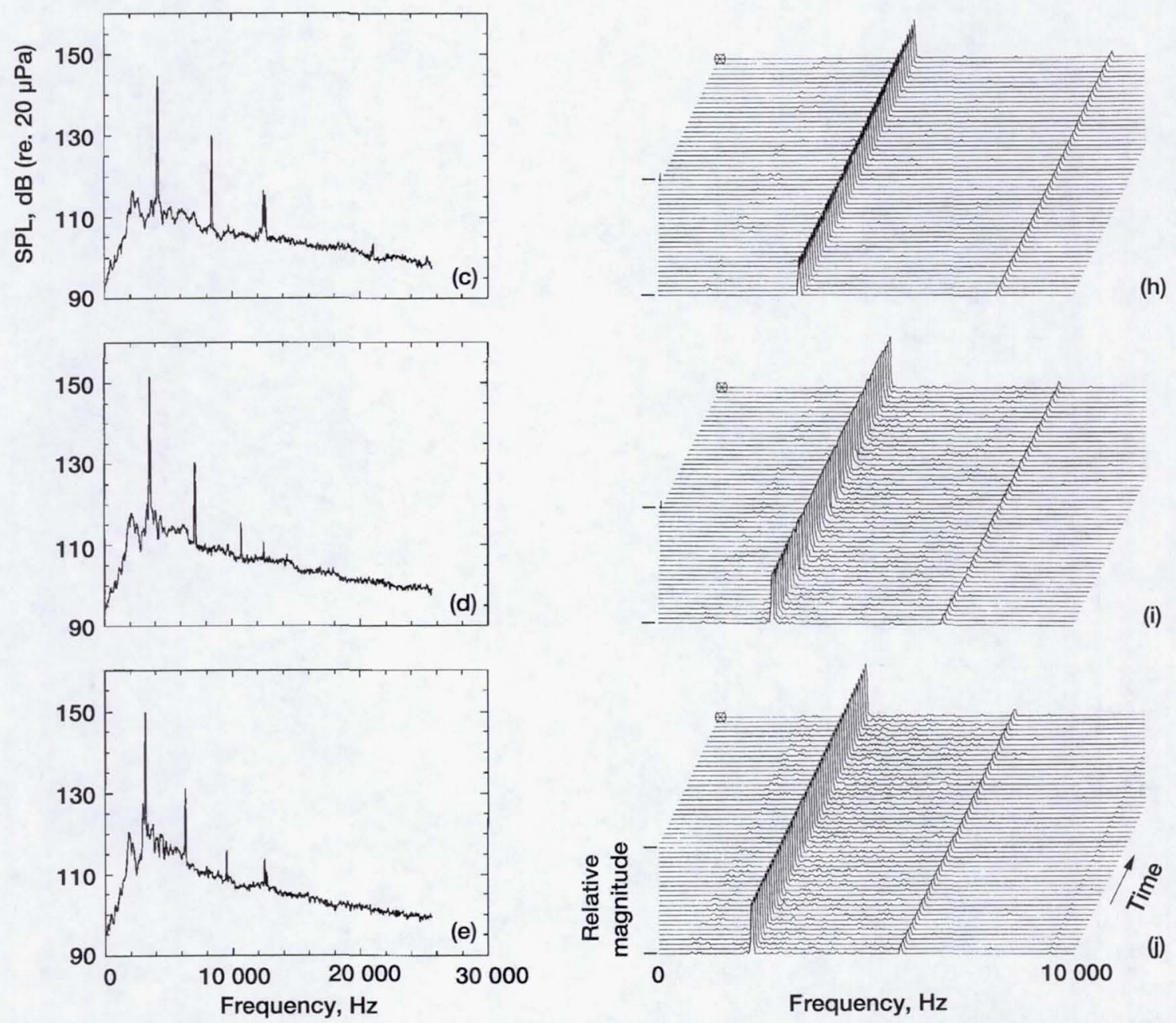

Figure 13.-Evaluation of screech unsteadiness by contrasting time-averaged spectra with a waterfall plot of instantaneous spectra for a jet from a rectangular nozzle with a straight exit. $M_{j}(a, f) 1.3,(b, g) 1.4$,

(c,h) 1.5, (d,i) 1.6, (e,j) 1.7. 

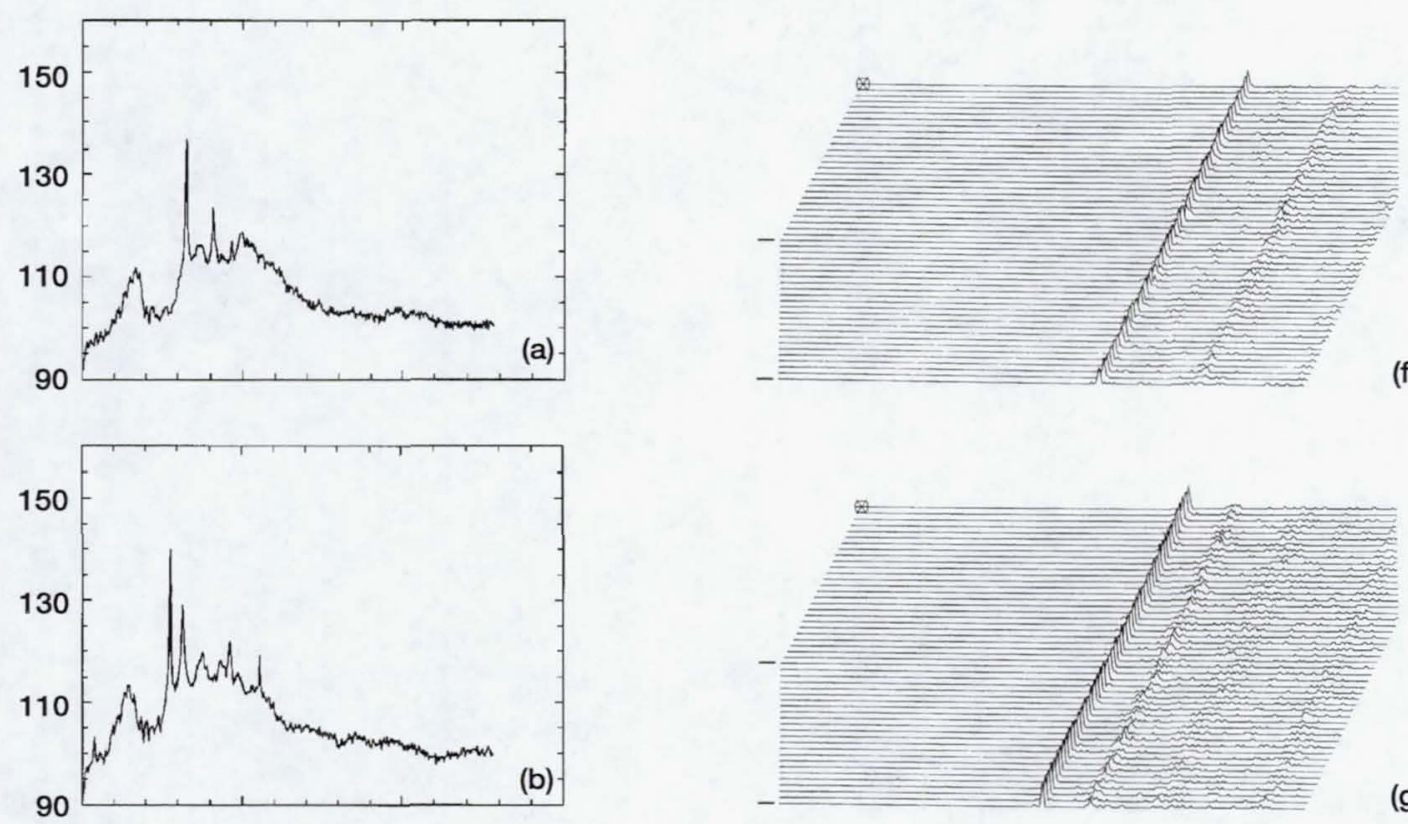

(g)
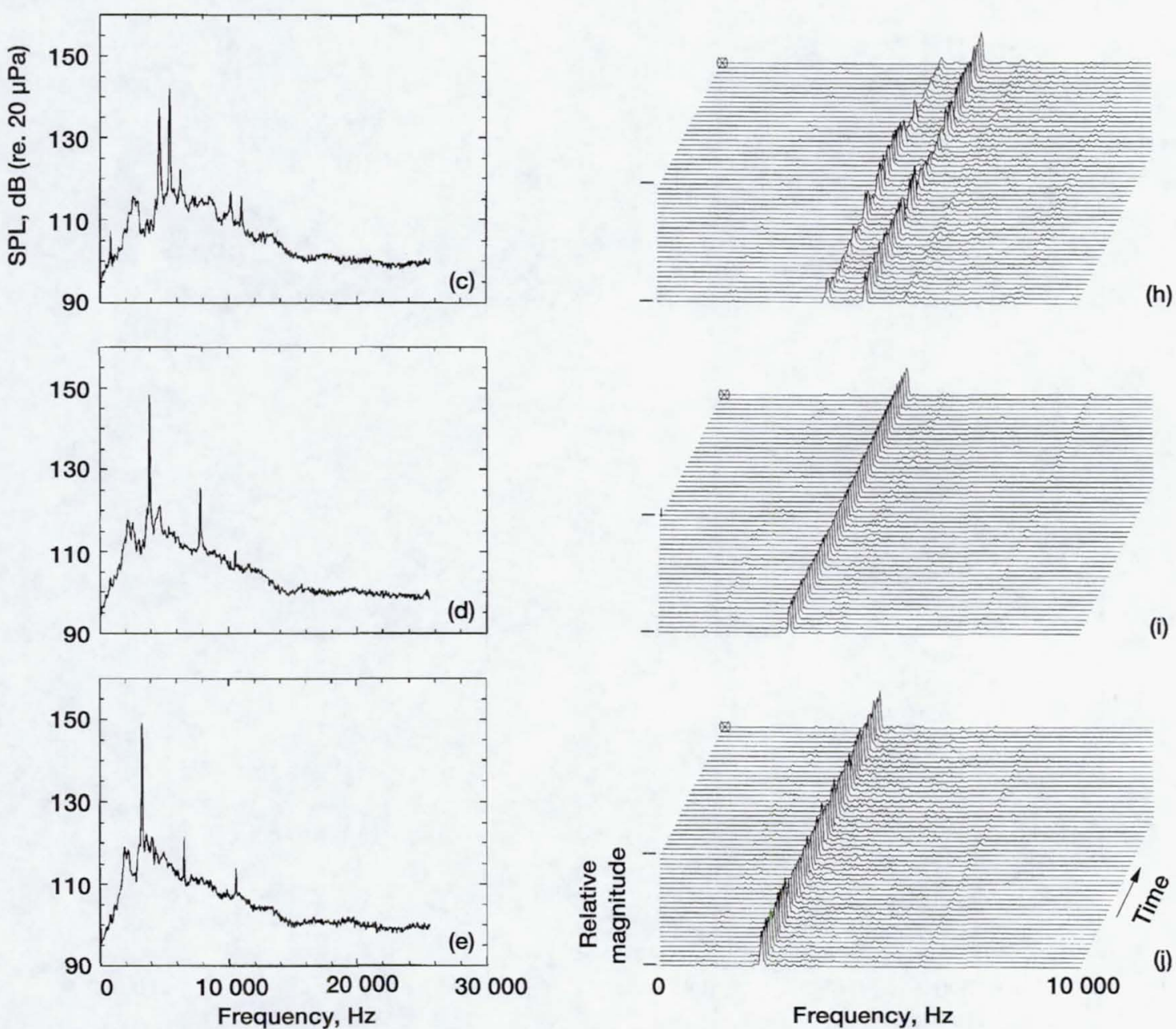

Figure 14.-Evaluation of screech unsteadiness by contrasting time-averaged spectra with a waterfall plot of instantaneous spectra for a jet from a rectangular nozzle with a single bevelled exit. $M_{j}(a, f) 1.3$,

(b,g) 1.4, (c,h) 1.5, (d,i) 1.6, (e,j) 1.7. 

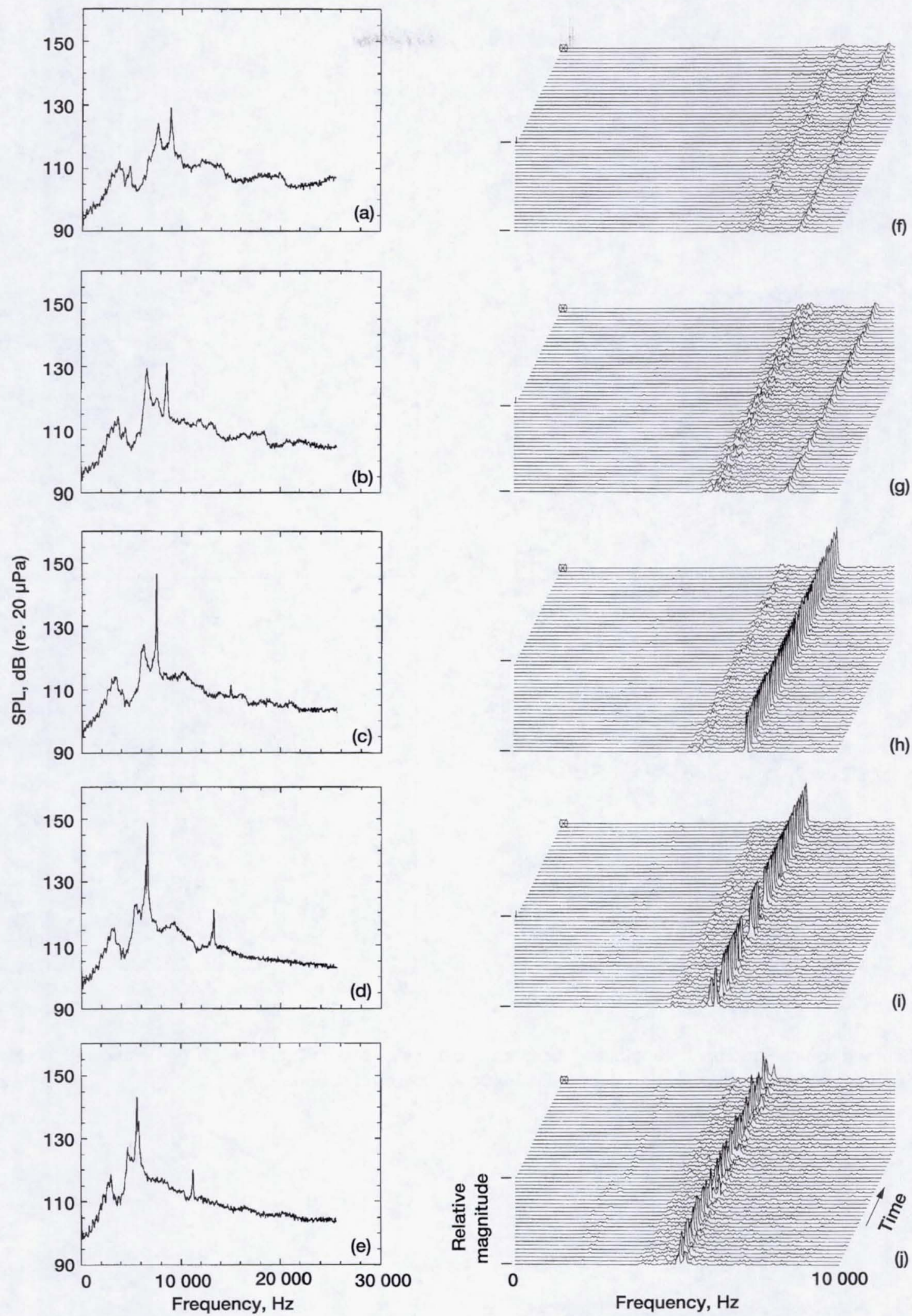

Figure 15.-Evaluation of screech unsteadiness by contrasting time-averaged spectra with a waterfall plot of instantaneous spectra for a jet from a rectangular nozzle with a double bevelled exit. $M_{j}(a, f) 1.3$, (b,g) 1.4, (c,h) 1.5, (d,i) 1.6, (e,j) 1.7. 


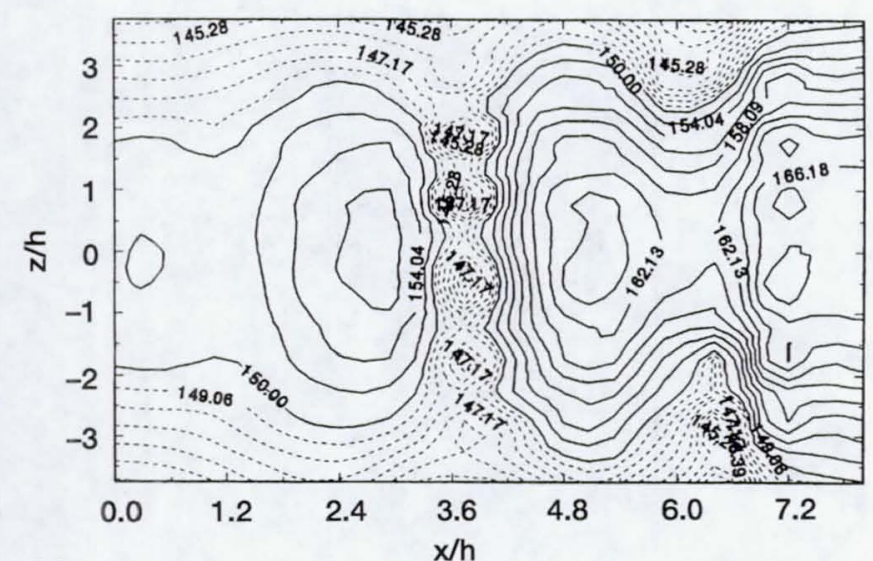

(a)

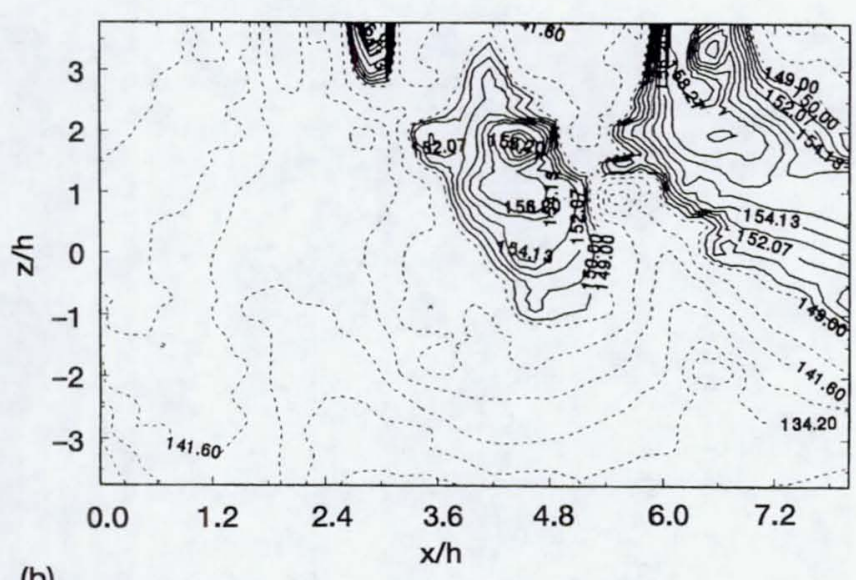

(b)

Figure 16.-Screech source structure, strength, and location. $x z$ plane was at $y / h=1.5, M_{j}=1.5$. (a) Rectangular nozzle with a straight exit, $(b, c)$ Single bevelled nozzle's dual mode, (d) Double bevelled nozzle.

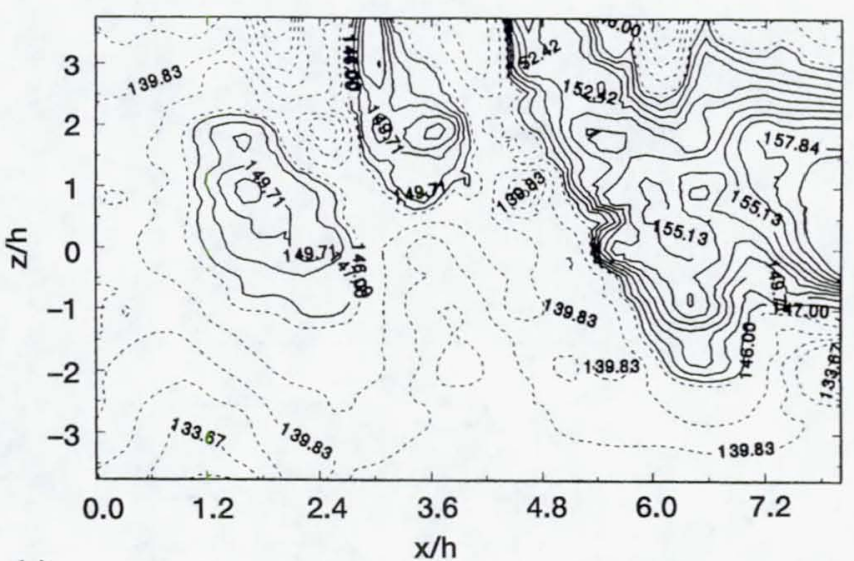

(c)

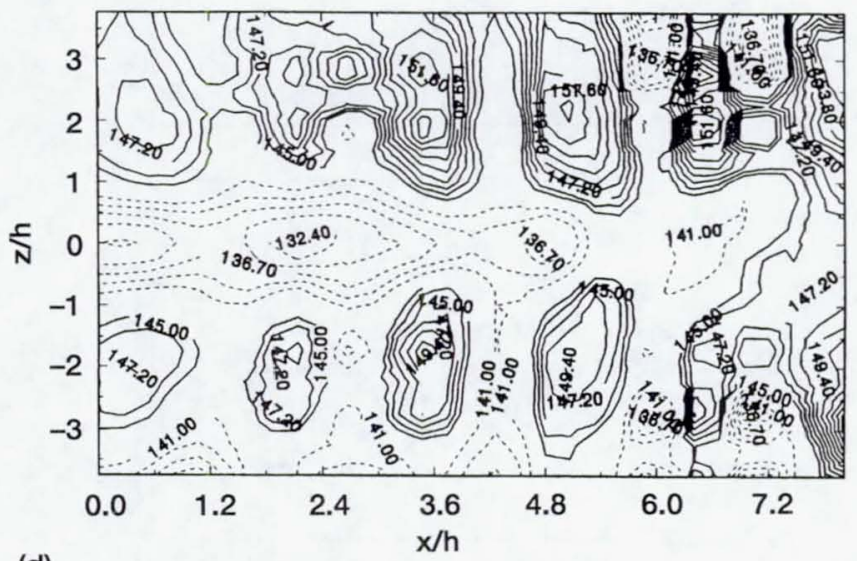

(d) 


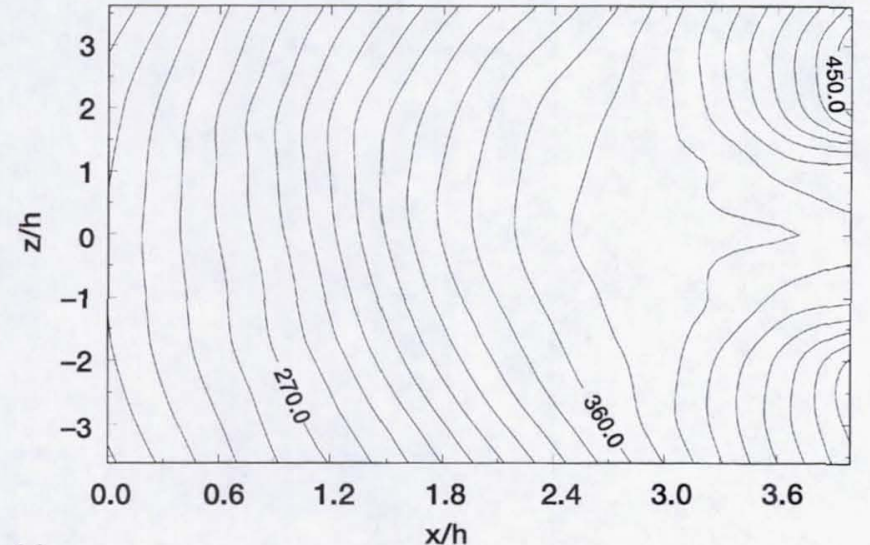

(a)

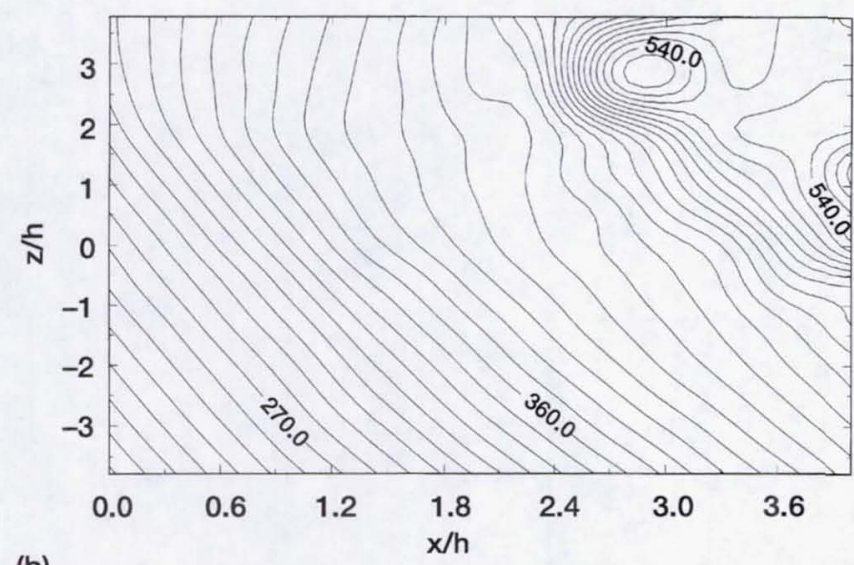

(b)

Figure 17.-Isophase contours of the spanwise varying screech modes. $x z$ plane was at $y / h=1.5, M_{j}=1.5$. (a) Rectangular nozzle with a straight exit, (b,c) Single bevelled nozzle's dual mode, (d) Double bevelled nozzle.

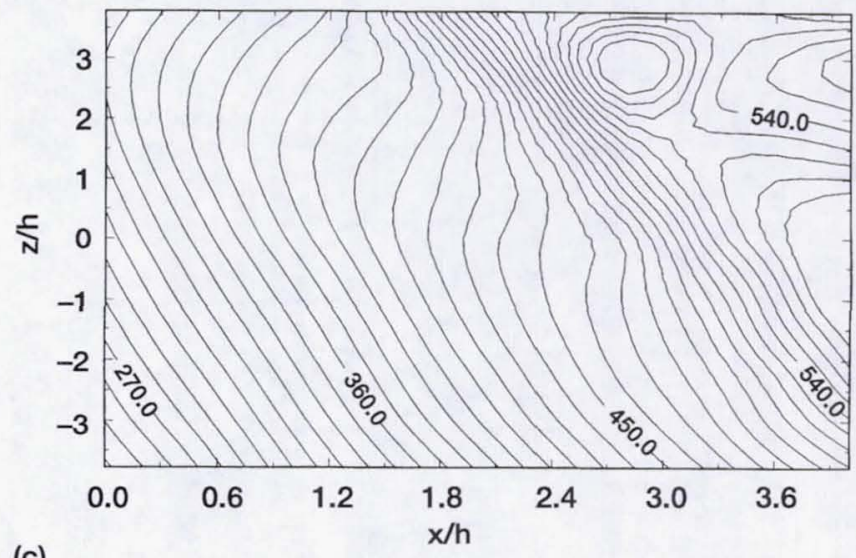

(c)

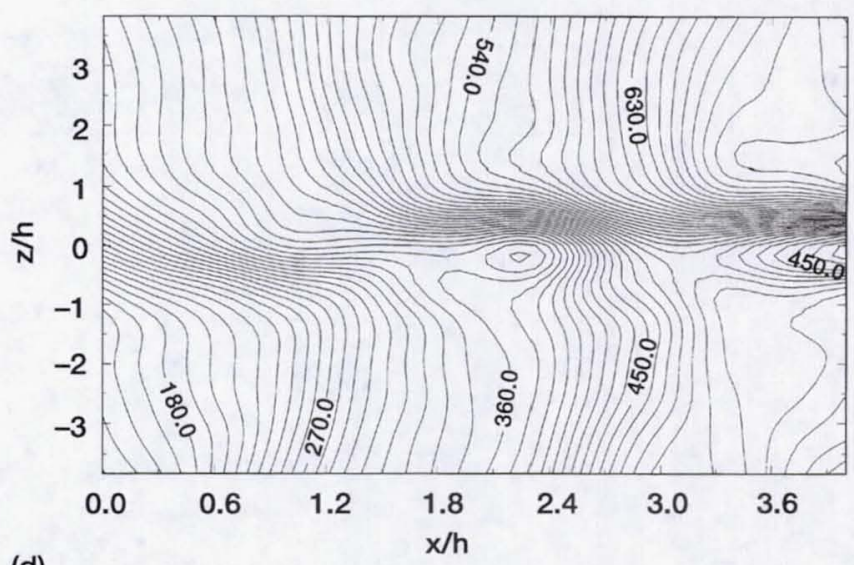

(d) 


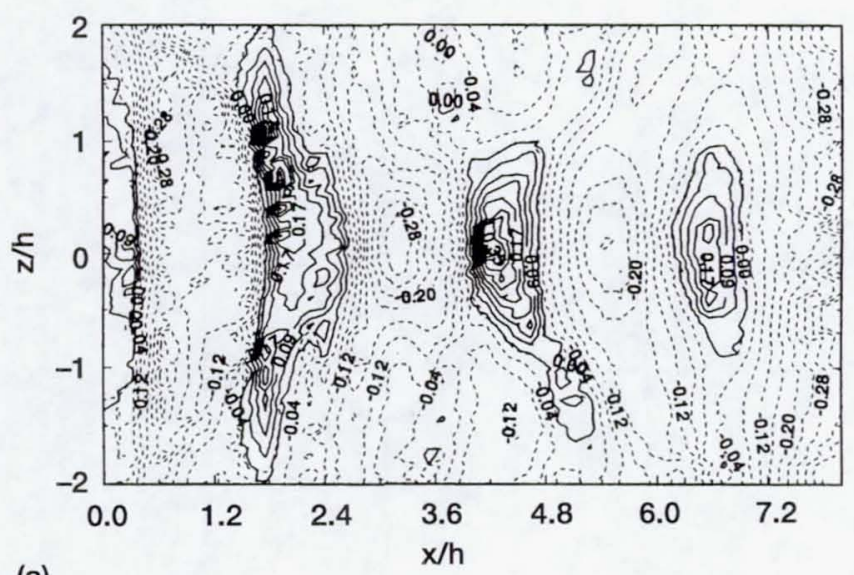

(a)

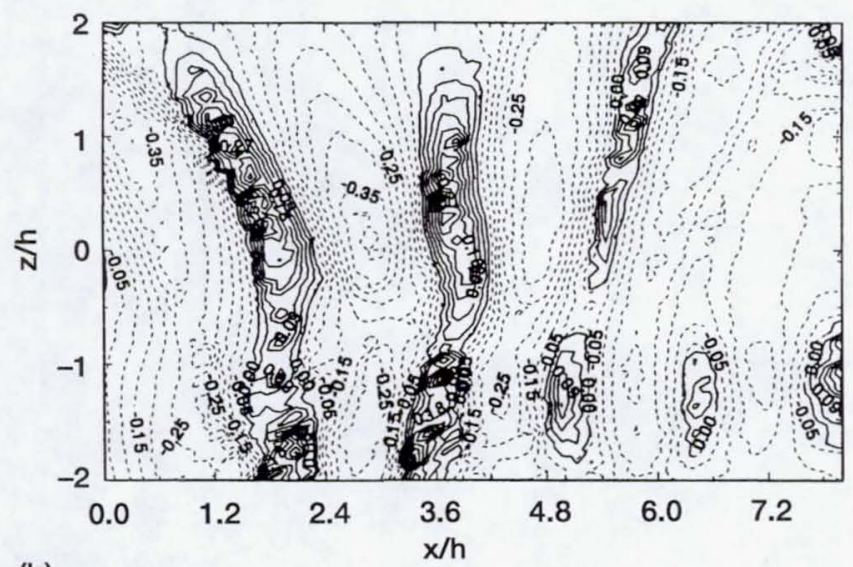

(b)

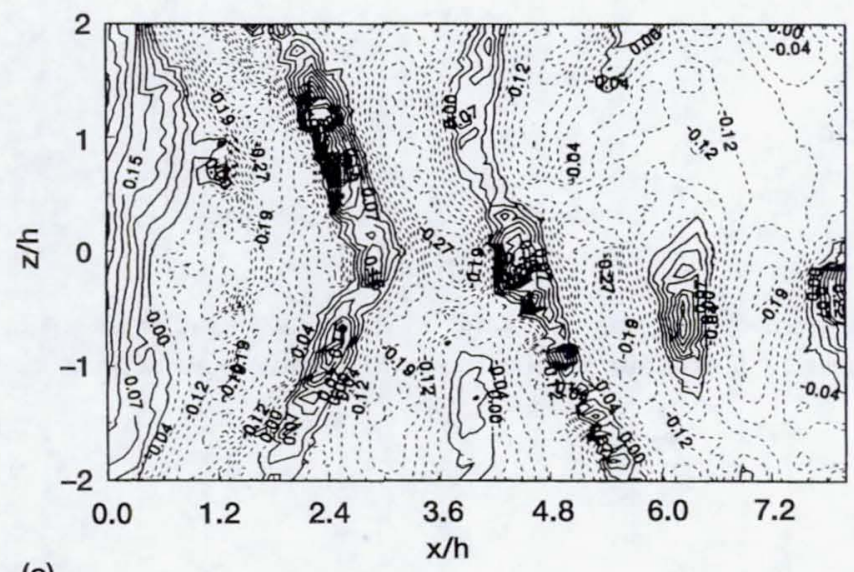

(c)

Figure 18.-Spanwise shock-cell structure corresponding to the screech amplitude and phase measurements in Figs. (16) and (17). (a) Rectangular nozzle with a straight exit, (b) Single bevelled nozzle, (c) Double bevelled nozzle. 


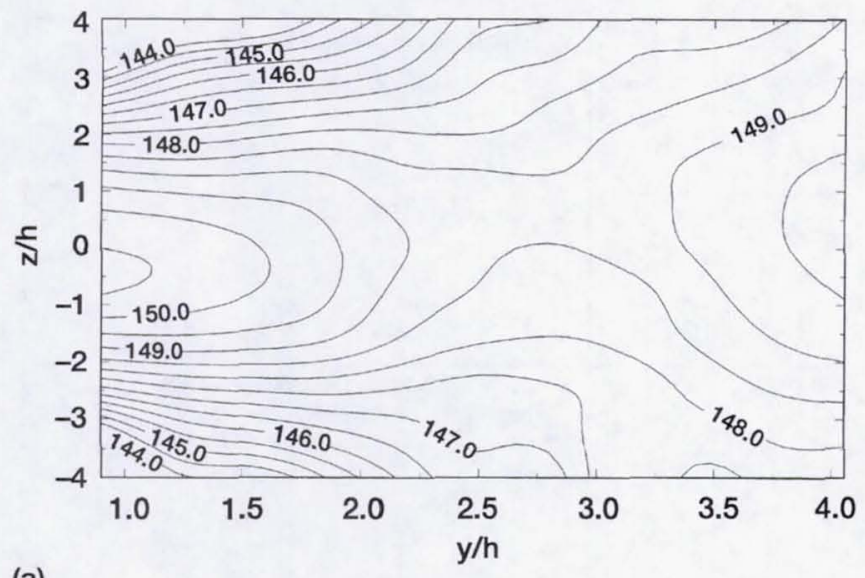

(a)

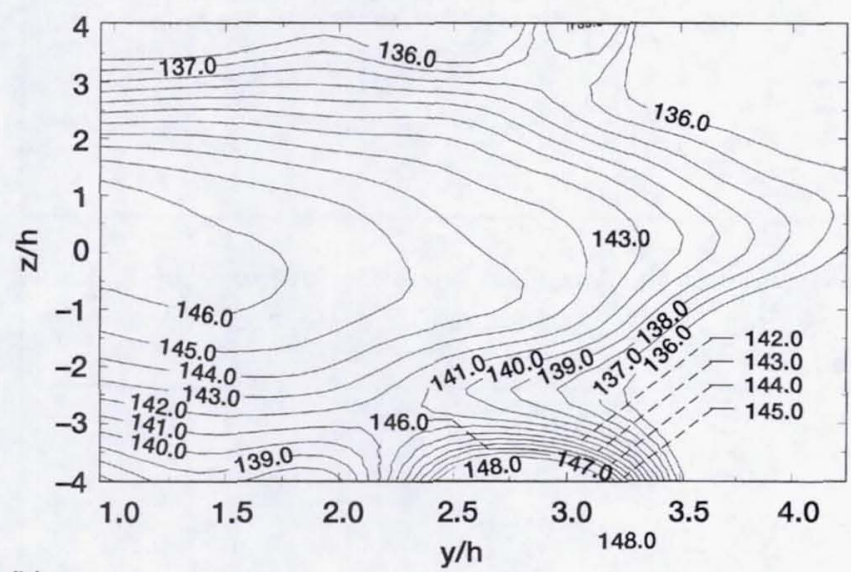

(b)

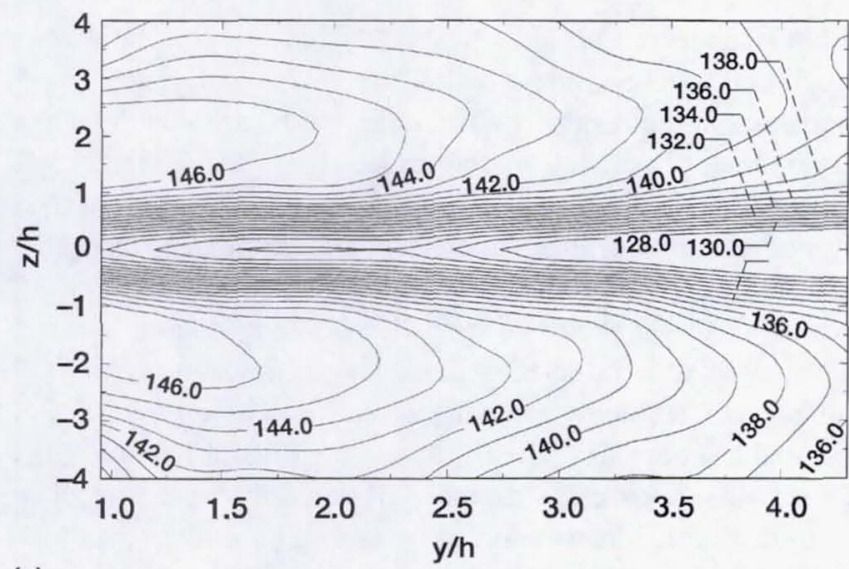

(c)

Figure 19.-Screech sound pressure levels (dB) and Isophase contours (in degrees) on the $y z$ plane at $x / h=-1.25$. (a-c) Sound pressure levels, (d-f) Isophase contours; (a,d) Jet from rectangular nozzle with a straight exit, (b,e) Single bevelled nozzle, $(c, f)$ Double bevelled nozzle.
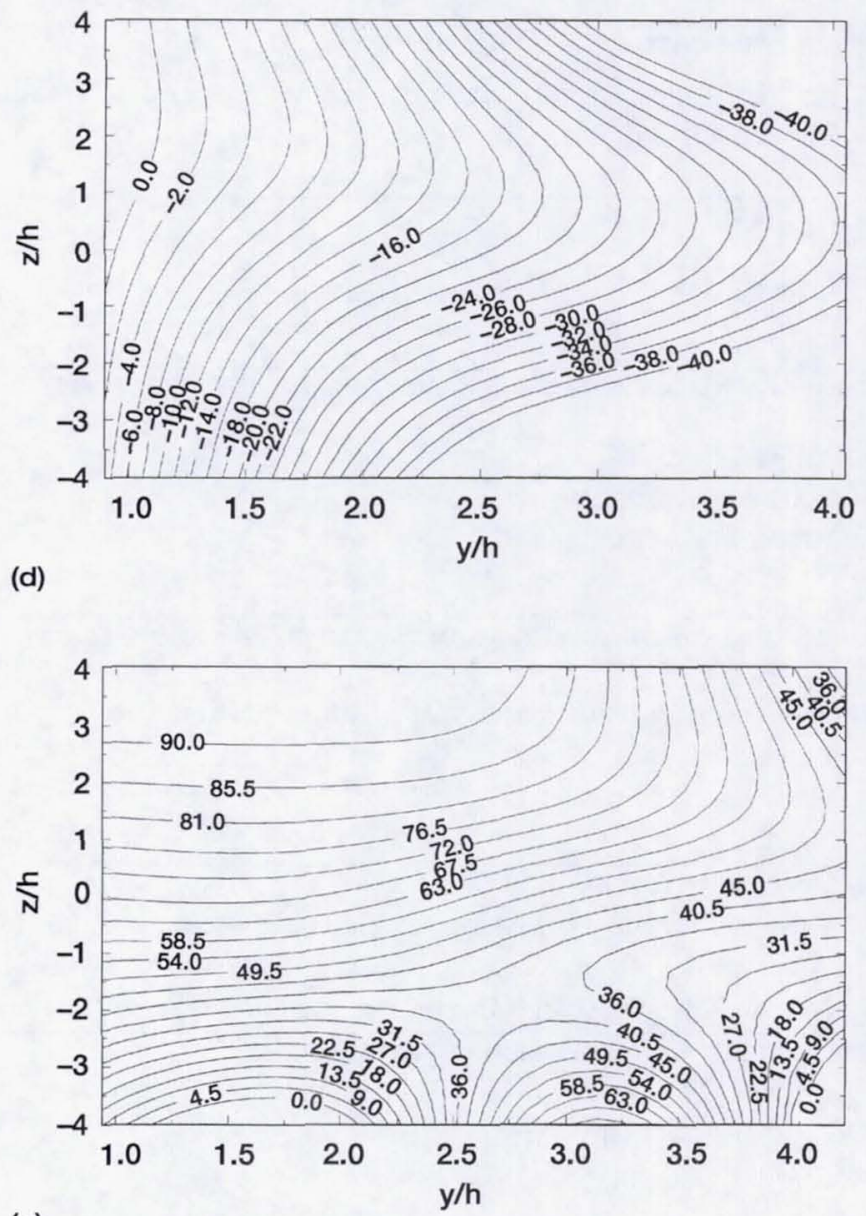

(e)

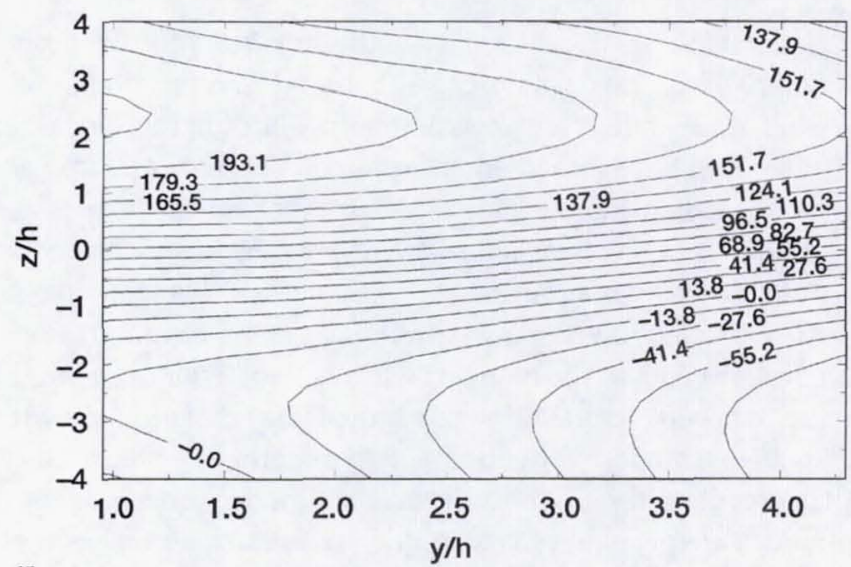

(f) 


\section{REPORT DOCUMENTATION PAGE}

Public reporting burden for this collection of information is estimated to average 1 hour per response, including the time for reviewing instructions, searching existing data sources, gathering and maintaining the data needed, and completing and reviewing the collection of information. Send comments regarding this burden estimate or any other aspect of this Davis Highway, Suite 1204, Arlington, VA 22202-4302, and to the Office of Management and Budget, Paperwork Reduction Project (0704-0188), Washington, DC 20503.

\begin{tabular}{|l|l|l} 
1. AGENCY USE ONLY (Leave blank) & $\begin{array}{c}\text { 2. REPORT DATE } \\
\text { September } 1996\end{array}$ & $\begin{array}{c}\text { 3. REPORT TYPE AND DATES COVERED } \\
\text { Final Contractor Report }\end{array}$ \\
\hline
\end{tabular}

4. TITLE AND SUBTITLE 5. FUNDING NUMBERS

Screech Tones From Rectangular Jets With Spanwise Oblique Shock-Cell Structures

\section{AUTHOR(S)}

Ganesh Raman

WU-505-62-52

C-NAS3-27186

7. PERFORMING ORGANIZATION NAME(S) AND ADDRESS(ES)

8. PERFORMING ORGANIZATION REPORT NUMBER

NYMA, Inc.

2001 Aerospace Parkway

Brook Park, Ohio 44142

E-9984

9. SPONSORING/MONITORING AGENCY NAME(S) AND ADDRESS(ES)

National Aeronautics and Space Administration

Lewis Research Center

Cleveland, Ohio 44135-3191

10. SPONSORING/MONITORING AGENCY REPORT NUMBER

NASA CR-198417

AIAA-96-0643

11. SUPPLEMENTARY NOTES

Prepared for the 34th Aerospace Sciences Meeting and Exhibit sponsored by the American Institute of Aeronautics and Astronautics, Reno, Nevada, January 15-18, 1996. Project Manager, John M. Abbott, Internal Fluid Mechanics Division, NASA Lewis Research Center, organization code 2600, (216) 433-3607.

12a. DISTRIBUTION/AVAILABILITY STATEMENT $\quad$ 12b. DISTRIBUTION CODE

Unclassified - Unlimited

Subject Category 02

This publication is available from the NASA Center for Aerospace Information, (301) 621-0390.

13. ABSTRACT (Maximum 200 words)

Understanding screech is especially important for the design of advanced aircraft because screech can cause sonic fatigue failure of aircraft structures. Although the connection between shock-cell spacing and screech frequency is well understood, the relation between nonuniformities in the shock-cell structures and the resulting amplitude, mode, and steadiness of screech have remained unexplored. This paper addresses the above issues by intentionally producing spanwise (larger nozzle dimension) variations in the shock-cell structures and studying the resulting spanwise screech mode. The spanwise oblique shock-cell structures were produced using imperfectly expanded convergent-divergent rectangular nozzles (aspect ratio $=5$ ) with nonuniform exit geometries. Three geometries were studied: (a) a nozzle with a spanwise uniform edge, (b) a nozzle with a spanwise oblique (single bevelled) edge, and (c) a nozzle that had two spanwise oblique (double bevelled) cuts to form an arrowhead-shaped nozzle. For all nozzles considered, the screech mode was antisymmetric in the transverse (smaller nozzle dimension) direction allowing focus on changes in the spanwise direction. Three types of spanwise modes were observed: symmetric (I), antisymmetric (II), and oblique (III). The following significant results emerged: (i) for all cases the screech mode corresponds with the spanwise shock-cell structure, (ii) when multiple screech modes are present, the technique presented here makes it possible to distinguish between coexisting and mutually exclusive modes, (iii) the strength of shocks 3 and 4 influences the screech source amplitude and determines whether screech is unsteady. The results presented here offer hope for a better understanding of screech and for tailoring shockcontaining jets to minimize fatigue failure of aircraft components.

14. SUBJECT TERMS

Screech; Shock-cells; Supersonic jets; Jet noise; Sonic fatigue

5. NUMBER OF PAGES

33

16. PRICE CODE

A03

\begin{tabular}{|c|c|c|}
\hline $\begin{array}{c}\text { 17. SECURITY CLASSIFICATION } \\
\text { OF REPORT }\end{array}$ & $\begin{array}{c}\text { 18. SECURITY CLASSIFICATION } \\
\text { OF THIS PAGE } \\
\text { Unclassified }\end{array}$ & $\begin{array}{c}\text { 19. SECURITY CLASSIFICATION } \\
\text { OF ABSTRACT } \\
\text { Unclassified }\end{array}$
\end{tabular}

NSN 7540-01-280-5500 